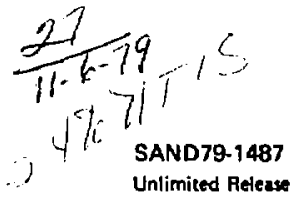

\title{
MASTER
}

\section{High-Temperature Complementary Metal Oxide Semiconductors (CMOS)}

John D. McBrayer

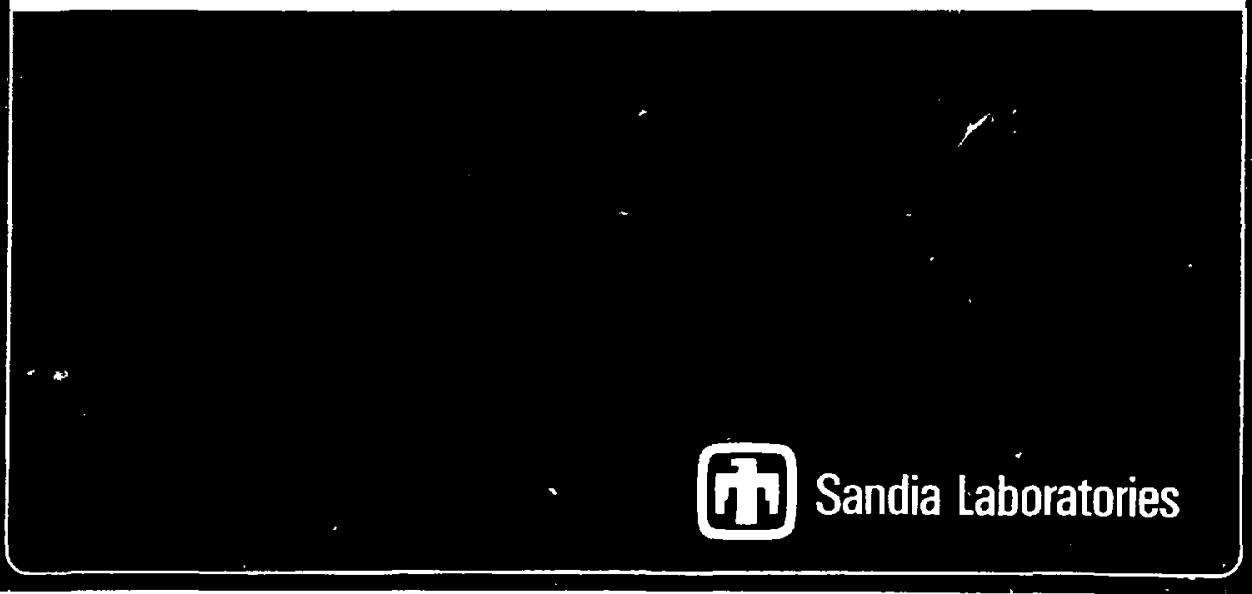

if 2900 O(7.73) 
SAND79-1487

Unlimited Release

\title{
High-Temperature Complementary Metal
}

Oxide Semi conductors (CMOS)

\author{
John D. McBrayer \\ Semiconductor Devices Division 2117 \\ Sandia Laboratories \\ Albuquerque, NM 87185
}

\begin{abstract}
Silicon cMos devices were studied, tested, and evaluated at high temperatures to determine processing, geometric, operating characteristics, and stability parameters.

After more than 1000 hours at $300^{\circ} \mathrm{C}$, most devices showed good stability, reliability, and operating characteristics.

Processing and geometric parameters were evaluated and optinization steps discussed.

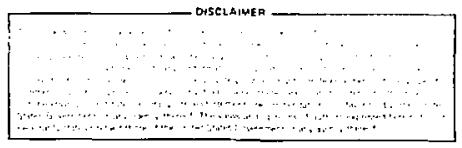


This page intentionally left blank. 
Introduction. . . . . . . . . . . . . . . . . . . 7

Physics and Processing. . . . . . . . . . . . . 8

Stability Data. . . . . . . . . . . . . . . . 17

Gate Voltage. . . . . . . . . . . . . . . . 17

Leakage Current . . . . . . . . . . . . . . . 18

Inverter. . . . . . . . . . . . . . . . . . . 20

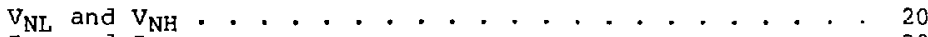

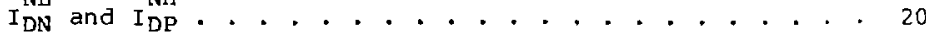

Results... . . . . . . . . . . . . . . . 20

optimization. . . . . . . . . . . . . . . . . . 21

Process (Doping Proflle). . . . . . . . . . . . . 21

Geometry. . . . . . . . . . . . . . . . . . . . 22

Conclusions and Recommendations. . . . . . . . . . . . 23

References. . . . . . . . . . . . . . . . 25

Appendix. . . . . . . . . . . . . . . . . . 26

High Temperature Process. . . . . . . . . . . . . 27

TC-1 Discrete Data. . . . . . . . . . . . . . . . 31

TC- I Inverter Data. . . . . . . . . . . . . . 44

TC-4 Test Chip. . . . . . . . . . . . . . . 53

Glossary of Technical Terms . . . . . . . . . . . . 54

Bibliography. . . . . . . . . . . . . . . . . 56

List of Figures

Figure l, . . . . . . . . . . . . . . . 9 9

Figure 2. . . . . . . . . . . . . . . . . . . . . . 18

Figure 3... . . . . . . . . . . . . . . . . 19

List of Tables

Table 1...................... . . 10

Table 2.................... . . . 13

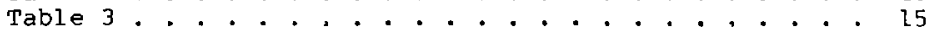

Table 4... . . . . . . . . . . . . . . . 16 
This page intentionally left blank. 
HIGH-TEMPERATURE COMPLEMENTARY METAL OXIDE SEMICONDUCTORS (CMOS)

\section{Introduction}

The theory on which silicon (Si) netal oxlde semiconductor (MOS) technology is founded states that this type semiconductor will perForm adequately at $300^{\circ} \mathrm{C}$. High temperature tests conductec on commercially-available MOS field-effect transistors (FET) have conEirmed this hypothesis. ${ }^{1-3}$ In this report we present the result:s of an investigation into the possibility of using CMOs technology at Sandia Laboratories (SLA) for high-temperature electronics. A CMOS test chip (TC) was specifically developed as the test bed. This test chip incorporates CMOS transistors that have no gate protection diodes; these diodes are the major cause of leakage in commercial devices.

We decided to use cMos technology because both $n$ - and $p$-channel devices could be evaluated. We also looked at small-scale integl ation, e.g., an inverter using CMos technology.

Theory and actual data have been compared before. 3 In this paper we intend to report on the aging and stability of cmos devices, especially where requirements call for minimal drift whon subjected to $300^{\circ} \mathrm{C}$ for 1000 hours. This drift must be less tha. that in devices taken from room temperature to $300^{\circ} \mathrm{C}$. 
Before developing circuits that nperated best at high temperature, different processing techniques were employed. These techniques, a's well as the best process, will be described below. We will also discuss geotetric and mask layout considections with respect to high-temperature applications.

\section{Physics and Processing}

Figure l shows a guard-ring junction-isolated type of CMos irverter. mhis is the technology we used in this study. The actual test chip has been described elsewhere, ${ }^{4}$ and we will not repeat it in this paper. Likewise, the physics of MOSFET technology has been documerter several times, 5,6 and we will present only those equations that we think are pertinent to this study' (see Table 1):

$$
\sigma_{t}=\frac{K T}{q} \text { in } \frac{N_{a}+\sqrt{N_{a}^{2}+4 n_{i}^{2}}}{2 n_{i}} \text { for the n-channel, }
$$

where $\quad n_{i}=\sqrt{N_{C} N_{v}} e^{-E_{g} k T}$,

$$
\begin{aligned}
& N_{C}=12\left[\frac{2 \pi n_{n}^{*} k T}{h^{2}}\right]^{i / 2}, m_{n}^{*}=\text { effective mass of electron, } \\
& N_{v}=2\left[\frac{2 \pi m_{p}^{*} k T}{h^{2}}\right]^{y /}, \text { and } m_{p}^{*}=\text { effective mass of a hole. }
\end{aligned}
$$



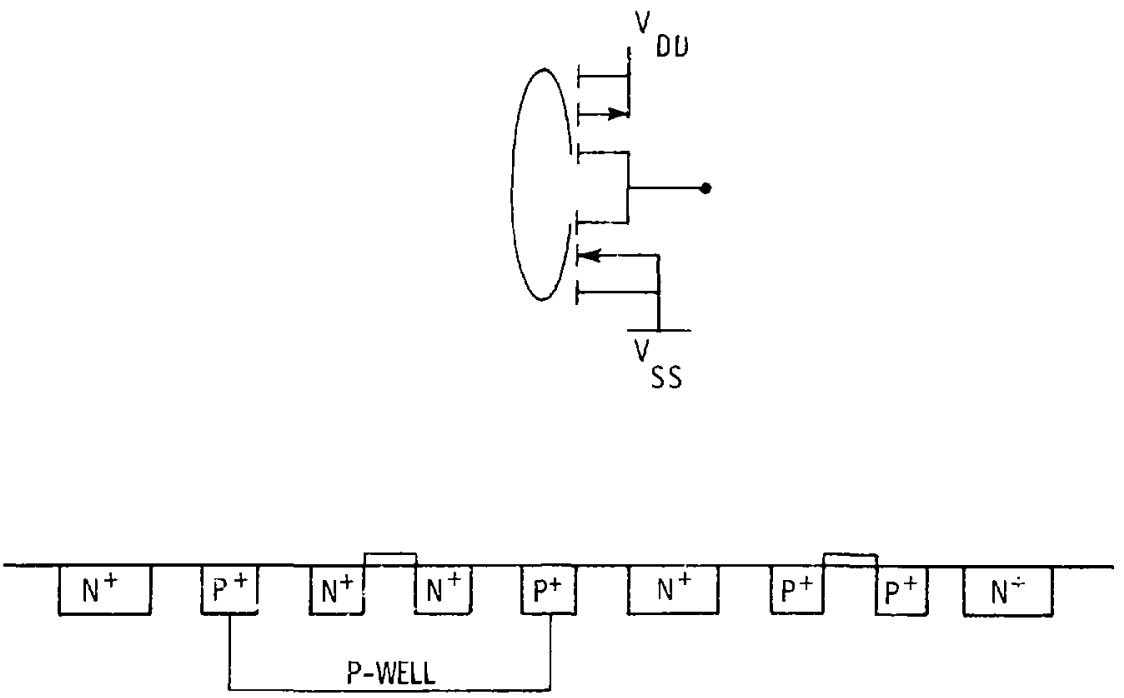

$N^{-}$

FIGURE 1

Guard Band Junction I solated CNOS

Inverter without Protection 
Summaly of laportanc MOS Equation: ing um and p-lianmel Transistors

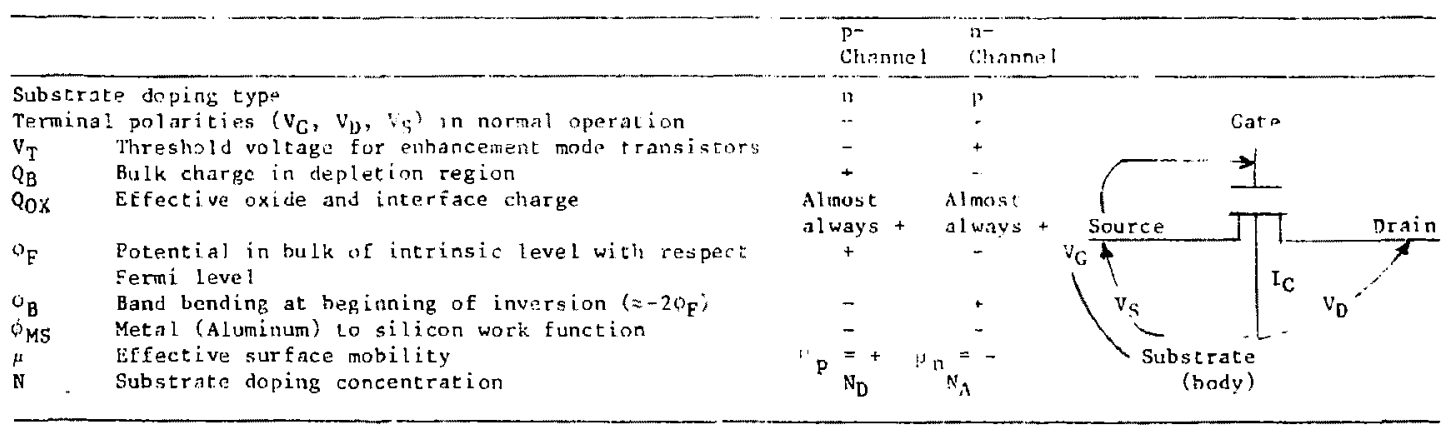

Threshold voltage

$$
\mathrm{Q}_{\mathrm{B}}= \pm\left(\mathrm{I}^{2} \mathrm{~F}_{\mathrm{S}} \mathrm{qN}\left[\mathrm{V}+\mathrm{o}_{\mathrm{B}}\right]\right) 1 / 2 \mathrm{~V}=\text { channel to substerce voitage }
$$

(v. Sor p.Channel, $v>0$ for n-Channe!)

Bulk depletion region charge*

$$
v_{y}=\sigma_{M S}+C_{B}-\frac{Q_{O X}}{C_{O x}}-\frac{Q_{B}}{C_{v x}}
$$

Derived from ReI. 7 
Nonsaturated, channe1 current

Campletc expression* $\quad \tau_{C}=c_{O X} \frac{w}{l}\left[\left[v_{G}-o_{M S}-o_{B}+\frac{Q_{O x}}{C_{O X}}\right]\left(v_{D}-v_{S}\right)\right.$

$$
-\frac{1}{2}\left(v_{D}^{2}-v_{S}^{2}\right)-\frac{2\left(z \epsilon_{B O N}\right)^{\frac{1}{2}}}{3 C_{O X}}\left(\left[\mp v_{D} \mp o_{B}\right]^{\frac{3}{2}}-\left[q_{S} \mp \dot{O}_{B} \frac{3}{2}\right)\right]
$$

$\underset{\text { Source at ground }}{\operatorname{simplified} \text { expression, }} \quad I_{C}=\mu C_{o x} \frac{W}{2}\left\{\left(v_{G}-v_{T}\right) v_{D}-\frac{1}{2} v_{D}^{2}\right\}$

Saturation, drain pinch-ofi

vol tage

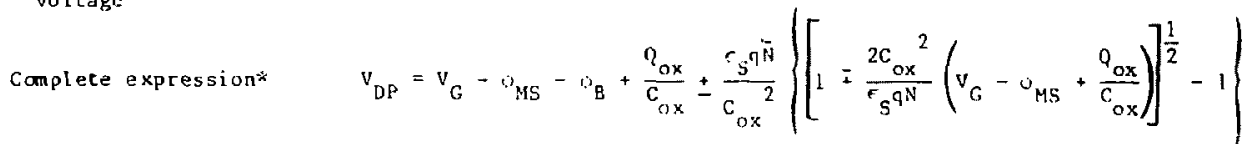

Simplified expression $\quad v_{D P}=v_{G}-v_{T}$

Saturation, channe $1 \quad T_{C P}=\frac{1}{2}, \mathrm{C}_{\mathrm{ox}} \frac{\mathrm{W}}{\mathrm{x}}\left(\mathrm{V}_{\mathrm{G}}-\mathrm{V}_{\mathrm{T}}\right)$ ?

current 
From the relationships expressed in these equations and general seniconductor phyuics, the following generalizations can be made:

As tomperature increases, the Fermi level moves toward the midile of the band gap, causing the built-in potential to decreasr, thereby decreasing the threshold voltage.

As temparature increases, the hand gap narrows, caising a minor increase in the intrinsic carrier concentration, $\left(n_{i}\right)$.

Carz ler mobility decreases vith increasing temperature, causira transconductance to decrease.

Inrreasing temperature increases leakage of generated and diffused curcents.

The Tore the doping, the greater the pariation ia threshold inlatgr as temperature increasos.

- The zoro temperature coefficient point occurs at higher gate voltaces as the doping is increased.

- The overalj. transconductance decreases capidly as temperature and doping increaso.

With these generalizations in mind, we made the process variations listed in Table 2 . 
Table 2

\section{Processing Variation}

Wafer

Substrate

$\underline{\text { p-we } 11}$

1

$$
.8-1.2 \cdots \mathrm{cm} n-t y p e
$$

Boron $50 \mathrm{keV} 7 \times 10^{13}$

$$
-5 \times 10^{15} \mathrm{~cm}^{-3}
$$

$$
\mathrm{N}_{\mathrm{S}}=4 \times 10^{16} \mathrm{~cm}^{-3}
$$

5

$$
.8-1.2 \text { ncm n-type }
$$

$$
-5 \times 10^{15} \mathrm{~cm}^{-3}
$$

$$
\text { Boron } 60 \mathrm{kev} 2 \times 10^{24}
$$

$$
\mathrm{N}_{\mathrm{S}} \cong 4 \times 10^{17} \mathrm{~cm}^{-3}
$$

7

$$
.2-.4 n-c \pi n \text {-type }
$$

Bo. on $60 \mathrm{keV} 1 \times 10^{14}$

$$
\sim 2 \times 10^{16} \mathrm{~cm}^{-3}
$$

9

$$
\begin{aligned}
& .2-.4 \Omega-\operatorname{cin} n-\text { type } \\
& \sim 2 \times 10^{16} \mathrm{~cm}^{-3}
\end{aligned}
$$

$$
\mathrm{N}_{\mathrm{S}} \doteq 2 \times 10^{17} \mathrm{~cm}^{-?}
$$

Boron $60 \mathrm{keV} 2 \times 10^{\mathrm{it}}$

$$
\mathrm{N}_{\mathrm{S}} \doteq 4 \times \mathrm{LO}^{17} \mathrm{~cm}^{-3}
$$

These variations are adjustments of the various doping levels that compose the MOSFETs, and they zequil any trade-offs ir, electica: performance, making optimization difficult fTables 3 and 4 . zable 3 shows that, although wafer 1 produces symmetrical gate voltages. leakage and transconductance tary greatly between the two channels. Wafer 9 performs well in leakage and voltage but not in transconductance.

All wafers except No. 5 performed as predicted by theory. The anomaly of wafer 5 remains unexplained. The tables show the average values derived after subjecting the wafers to $300^{\circ} \mathrm{C}$ for 1000 hours. 
Threahold voltages for the strviving dovices are within 40.1 of those listed in rabler 3 and 4 ; leakages are within \pm 5 .. A ol those listed in Tablo 3 , and 25 1. A of those in Table 4 (see Appendix). Acoordine to theory, the following pattern should appear:

- For wafers 1 and 5, p-channel data should be similar.

- Eor wafers 7 and 9, p-channel data should be similar.

- For wafers 5 and $7, n$-channel data should be similar. 
Table 3

TC- 1 Process Comparison at $300^{\circ} \mathrm{C}$

\begin{tabular}{|c|c|c|c|c|c|c|}
\hline \multirow[b]{2}{*}{ Wafer } & \multirow{2}{*}{$\begin{array}{r}\text { Average } \\
(1, \mathrm{~A}) \\
\mathrm{n} \text {-Channe l } \\
\end{array}$} & \multirow{2}{*}{$\begin{array}{l}\text { Leakage } \\
\text { p-Channel }\end{array}$} & \multirow{2}{*}{$\begin{array}{r}\text { Average Gate } V \\
n \text {-Channel }\end{array}$} & \multirow{2}{*}{$\begin{array}{l}\text { Lape }\left(V_{G}\right) \text { o } 10 . \mathrm{A} \\
\mathrm{p} \text {-Charnel }\end{array}$} & \multicolumn{2}{|c|}{$\begin{array}{c}\text { Average Transconduct ance } \\
\text { (mmhos) }\end{array}$} \\
\hline & & & & & n-Channe I & $p$-Channel \\
\hline 1 & 12.41 & 18.85 & 1.45 & -1.45 & 0.45 & $0.2 \%$ \\
\hline 5 & 21.44 & 25.86 & 2.72 & -1.26 & 0.22 & 0.26 \\
\hline 7 & 3.90 & 6.15 & 1.60 & -2.41 & 0.34 & 0.21 \\
\hline 9 & 4.43 & 6.07 & 2.56 & -2.50 & 0.10 & 0.14 \\
\hline
\end{tabular}


Tabio 4

\begin{tabular}{|c|c|c|}
\hline Avtrage Leakage & Average $V_{\mathrm{C}}$ \& $100 \ldots \mathrm{A}$ & 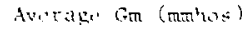 \\
\hline
\end{tabular}

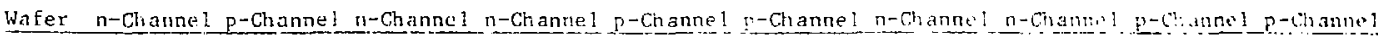

\begin{tabular}{|c|c|c|c|c|c|c|c|c|c|c|}
\hline 1 & 280 & 460 & $1.54^{\prime}$ & 1.55 & -.79 & -.78 & 1.10 & 1.07 & 1.82 & 1.75 \\
\hline 5 & 88 & 163 & 3.08 & 3.08 & -1.18 & -1.21 & 0.61 & 0.61 & 1.79 & 1.74 \\
\hline 7 & 107 & 139 & 1.77 & 1.78 & -2.12 & -2.14 & 1.07 & 0.99 & 1.27 & 1.27 \\
\hline 9 & 88 & 139 & 2.77 & 2.49 & -2.02 & -2.22 & 0.66 & 0.68 & 1.16 & 1. 1: \\
\hline
\end{tabular}

TC-4 Process Comparisun at $30,0^{\circ} \mathrm{C}$ 
The tables show that, except for wafer 5, the theory and the actual data generally agree.

The guard-ring, junction-isolated cmos process is quite clean and uses $Q_{S S}, N_{S t}$ reduction techniques and other schemes lo reduce oxide contamination. ${ }^{8-1]}$ For example, by annealing with $\mathrm{N}_{2}$ we decrease $Q_{55}$, and by annealing with $\mathrm{H}_{2}$ we decrease $\mathrm{N}_{\mathrm{St}}$. Careful and clean processing decreases sodium and potassilim contamiration. The circuits were metallized with standard aluminum 1 um thick, and standard p-glass passivation was used over the metal. The components were packaqed in a ceramic, 16-pin Elat pack. A computer printout of the process is included in the Appendix.

\section{Stability Data}

Although we will not discuss all the parameters tested, as an indication of stability, we will discuss data for gate voltage at $10 \mathrm{LA}(\mathrm{TC}-1)$ and $100 \mathrm{iA}(\mathrm{TC}-4)$, and leakage currents.

\section{Gate Voltage $\left(V_{G}\right)$}

To determine gate voltage, each transistor was measured separately. The source and substrate were innected to ground, and the drain was connected to an $8-V$ source. The voltage on the gate was slowly increased until $10 \mu \mathrm{A}$ was measured betwe-n source and drain; this voltage was recorded (Figure 2). 


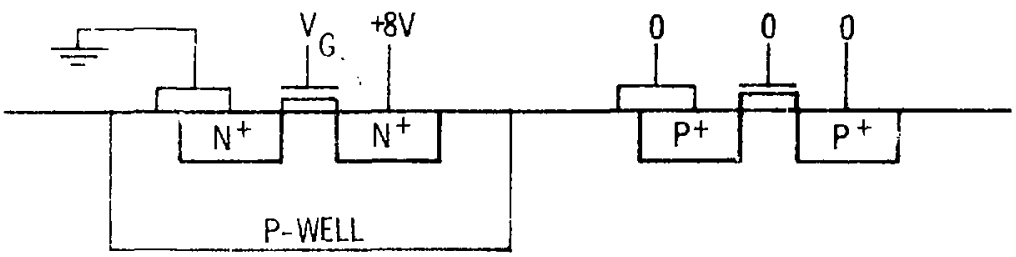

$\mathrm{N}^{-}$

FIGURE ?

Gate Voltage Measurement Setup

rho :0 is an includes the reverse leakage curent from drain to 3ubstale bil not rom p-wall to n-surjerate. In all date obtained, 10. $\lambda$ was not exrerted in the gate voltages neasured for TC-1 (1) A) or for TC-4 (100 A). See Table 4.

\section{Leakage current}

The ientage currorts discussed are drain-to-source channel leakage, Aain-to-substrate reverse bias leaiage, and p-weil to r-substrate leakage. They were measured with the transistors connectes as a CMOS inverter. With one transistor biased strongly on, ie then reasured the current that the other transistor allowed to Jass while it is turned off (Figure 3 ). Thus, we have a worst-case measurement for leakage. In all cases, leakage was small enough 'It, In to allow the semiconauctor to remain useful in actual circuits. 


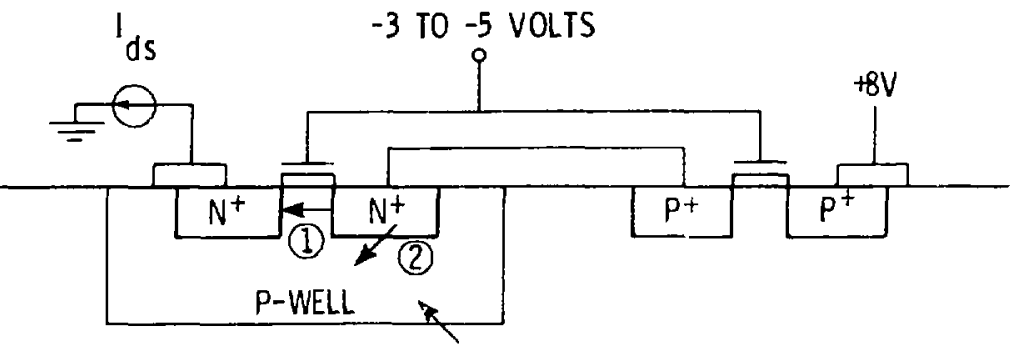

(3)

$\mathrm{N}^{-}$

FIGURE 3

Measurement of Leakage Current for $n$ Channel

(1) Drain to source Leakage

(2) Drain to p-well Leakage

(3) P-well to n-substrate teakage

This type data is shown in the Appendix for TC-1. In all cases, we determined that the $n$ - and p-channel devices were reasonably stable and functional except for wafer 5 which remains an unexplained anomaly.

wafer 9 demonstrated good stability, low lakage, and a reasonable $V_{G}$ at 10 if on both the $n$ - and p-channel devices. TC-4 data supports this finding but has an order of magnitude inrrease in leakage because of its larger size. 
Data from transistors connected as inverters, show that they will perform as a small-scale integrated circuit (SSIC) at high

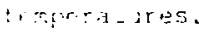

$V_{1}=$ and $V_{\text {NH }}$

In this test, we measured the output voltage with the inputs at $1.5 \vee\left(\mathrm{V}_{\mathrm{NI}}\right)$ and $3.5 \mathrm{~V}\left(\mathrm{~V}_{\mathrm{NH}}\right)$ obtaining functionality and noise nargin parameters.

Tn: a:d T in:

H:t? these tests we determined the drive current capability of s:- an p-channo devices when hooked together as an inverter.

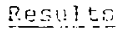

The data for inverters, listed in the Appendix, show that all Fonesses were functional at $300^{\circ} \mathrm{C}$ after $1000 \mathrm{hrs}$. In all cases, ir $\because$ currents decreased with increasing temperatures as theorized; =: ar- is lost to ground through several leakage paths (Figure 3 ) $\therefore \quad$ :enperature increases.

: in:ng from the data obtained, there seems to be no outstanding $\therefore \therefore-\therefore$ one process over the other. There should be more 
dynamic testing to determine this. The data do suggest that drive currents for the higher-doped devices (wafer 9) are more symmetrical for a given geometry and are less temperature dependent than lowerdoped devices. Furthermore, cmos, when digitally operated, works in a complementary mode; that is, when one transistor is on, the other is off. This is helpful for reliable high-temperature performance because it allows both devices to go depletion yet stili perform a given digital function (Figures 2 and 3 ). Therefore, we can leave the threshold voltages closer to zero than when the devices musi remain enhancement at $300^{\circ} \mathrm{C}$, making higher speed devices nossible. Wafer 5 has not been discusseo because of its unexplainable behavior: $V_{N L}$ and $V_{N H}$ data from wafer 9 was inacivertently destroyed.

\section{Optimization}

Many trade-offs are necessay to determine the best way to build high-temperature cMos circuits. The principal parameters that must vary are doping profiles and size; oxide growth and overall cleanliness make the circuit possible.

\section{Process (Doping Profile)}

Judging from the results of this study, doping profiles like: those of wafers 7 and 9 are best for high-temperature use. Application is extremely important because we must know what is expected from the circuit before the right process is found. For example, wafer $9\left(\mathrm{n}^{-} \mathrm{sub} \approx 2 \times 10^{16} \mathrm{~cm}^{3}\right.$ and $\mathrm{p}$-well $\mathrm{N} \mathrm{s} \approx 4 \times 10^{17} \mathrm{~cm}^{-3}$ ) 
might appear :o be tie best choice for h.gh-temperature electronias--it has good symmetry, exhibits small variaticn with temperature, and has reasonable drive-curcent capability. However, in some anflications, it may have too high a threshold voltage and too low a reabiown voltaye $(\sim 12 \mathrm{~V})$. Therefore, depending on the cirsuits used, increasing the doping to increase the temperature range of the CMos does not always produce an ideal circuit. In fact, some electrial requirements may make it impossible to develop a highlonneratare circuit by using silicon planar technology.

An improvement in processing would be to use laser ${ }^{22}$ irstead of thermal annealing (not done in the study). This woula decrease inakage ard increase switching speeds by doing a better job of repaicin: the damage causer by implantation, i.e., decrease trapping sights and improve the crystalline structure.

\section{Geometry}

When desiqnirg the mask. set for high-temperature circuits, we must include severa\}. considerations not necessary when designing roor: temperature circuits. For example, of major importance is the fact that the area between the p-well and the n-substrate must be as sall as possible to decrease reverse leakage. This means that each n-chanrel transistor should have its own p-well. The price for this is ar. undesirable increase in the silicon area. 
The mobility of holes and electrons decreases with increasing temperature but not at exactly the same rate. However, the ratio of $Z / L n$-shannel to $Z / L$ p-channel should be the same as in room temperature circuits to keep the circuits complementary. Keeping their ratio the rame as in room-temperature circuits seems to be a dool comprom ise.

For high-temperature circuits, the area from the drain to the substrate junction should be as small as possible to decrease reverse leakage. This is accomplished by horseshoeing the $7 /$ Ls, thereby increasing circuit density--this method is already in common use.

To make high-temperature circuits more reliable, metal lines should be as broad and deep as possible, again sacrificing chip area.

\section{Conclusions and Recommendations}

Existing cMos technology can be used to produce stable and useful circuits that operate at $300^{\circ} \mathrm{C}$ for 1000 hours, This accomplishment, however, sacrifices some chip area and does not provide gate protection. For this latter problem, high-temperature GaAs and Gap diodes should be developed as protection devices. Although these diodes would probably be outside the cmos chip, they could be pact of the same Elat pack. 
The behavior of wafer 5 remains unexplained; however, processing and testing will continue in an effort to explain this anomaiy.

More complicated SSIC will be studied to determine how well or how Far junction iso ation will operate, and different gate materials wili be investiqated. 


\section{References}

1. J. L. Prince of Clenson University, Investigation of the Performance of Semiconductor Devices at Elevated Temperatures, Sandia Laboratories, Albuquerque, New Mexico, under Contract No. 06-4336, November 1977.

2. D. W. Palmer, B. L. Draper, J. D. McBrayer, and K. R. White, Active Devices for High-Temperature Microcircuitry, Sandia Labsratories, Albuquerque, New Mexico, SAND77-1145, February 1978.

3. B. L. Draper and D. W. Palmer, "Extension of High-Temperature Electronics," Proceedings of ECC, (1979).

4. J. D. McBrayer, CMOS Test Chips, Sandia Laboratories, Albuquerque, New Mexico, SAND78-1390, August 1978.

5. A. S. Grove, Physics and Technology of Semiconductor Devi-zes, (New York: John Wiley and Sons, Inc., 1967).

6. S. M. Sze, Physics of Semiconductor Devices, (New York: wilcy-Interscience, 1969).

7. W. M. Penney and I. Lau, MOS Integrated Circuits, (New York: Van Nostrand Reinhold Company, 1972).

8. D, Leistiko, Jr., A. S. Grove, and C. T. Sah, "Electron and Hole Mobilities in Inversion Layers on Thermally oxidized Silicon Surfaces," IEEE Trans Electron Devices, 248 (May 1965).

9. F. N. Schrieffer, "Effective Carrier Mobility in Surface-space Charge Layers," Phys. Rev., 97, p. 641 (1955).

10. W. M. Bullis, "properties of Gold in Silicon," Solid-state Electronics, 9, D. $143(1966)$.

11. B. E. Deal, et al., "Characteristics of the surface state Charge (Qssi of Thermally Oxidized Silicon," Electrochem. Soc., 144, p. 266 (1967).

12. C. W. White, J. Narayans, and R. T. Young, "Laser Annealing of Ion-Implanted Semiconductors," Science, 204(4382):461, May 1979. 


\section{Appendix}

High Temperature Process

TC-1 Discrete Data

TC-1 Inverter Data

TC-4 Test Chip 


\section{ADPENDIX}

\section{High Temperature Process}

1. BASIC SUBSIRATE

2. OXIDE ETCH: TLB DIFFUSION AND OXIDATION

3. OXIDE ETCH: SOURCE AIVD DRAIN DIFFUSION AND OXIDATION FOR P-CHANNEL DEVICE

4. EICH: DIFFUSION OF N-CHANANEL SOURCE AND DRAIN AND OXIOATION

5. ETCH: GROWTH OF GATE OXIDE; FOLLOWED BY CONTACT CLUTS AND METALLIZATION
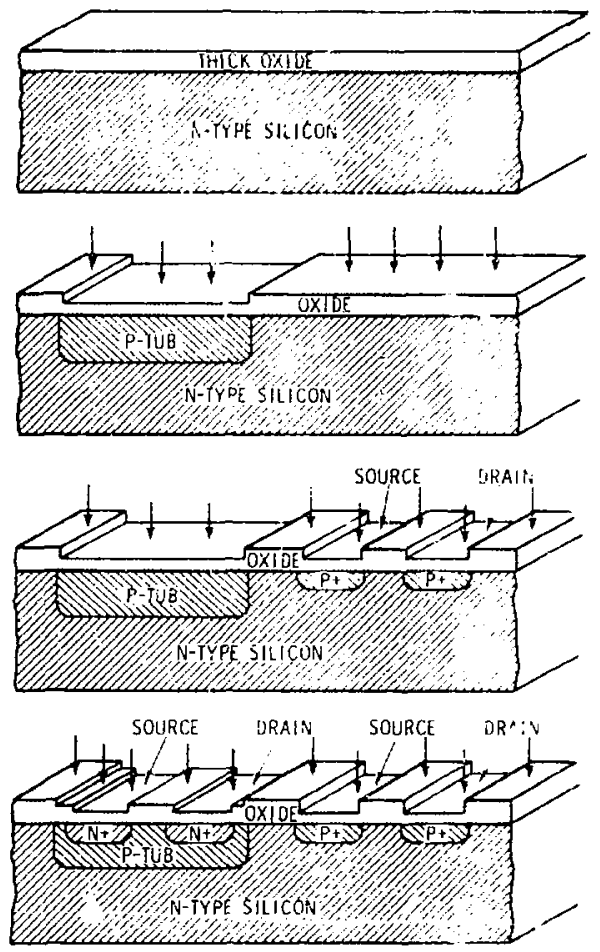

- METALLIZATION

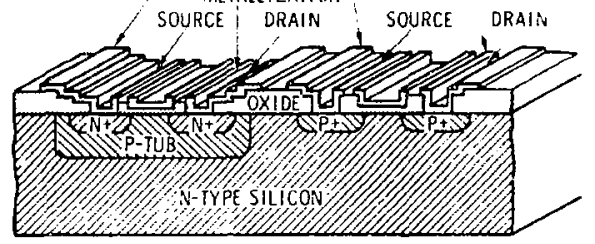


High temperature Process

step

\section{Process}

No.

Nafers

$11.06 \mathrm{Bh}$

CIJEAN W/SCRUB

25

DRY/STEAM OX, 15/90

25

$747 / 50$, LEVl, 3.5S, A

25

TX-1.00 PRE-VE.T

25

$\mathrm{P} \mathrm{I}^{2} \mathrm{CH} \mathrm{Cl} \mathrm{H} \mathrm{POO}+\mathrm{I} \mathrm{M}$, NOTE 4

INSPGCTION

25

CLEAN $W / S C R U B$

25

DRY OX, 6OM

25

IMP $W 1,2+\mathrm{Cl}, 3$,

IMP, NOTE 5

IMP, NOTE 6

8

ETCH, 4M

25

CLEAN

2 ,

P-WEI,L DRY, $16 \mathrm{H}$

$747 / 60$, LV2, 3.5S, A 25

TX-100 PRE-IVET

25

ETCH, C2 $\mathrm{HPO}+1 \mathrm{M}, \mathrm{A}$

MEAS CHAN CD 25

INSPECTION 25

CLEAN W/SCRUB

$P+$ PREDEP, NOTE I 25

BORON GLASS ETCH 25

DRY/STM 25

STAIN REMOVAL 25

DRY OX, 30M, 1G00C 25

CVO OX, 3.5-4.5K, FRNT 25

$747 / 60$, LV3, 3.55, A 25

TX-100 PRE-WET 25

ETCH, NOTE 7

MEAS CHAN CD, 7.7 MIC 25

INSPECTION 25

CLEAN W/SCRUB 
High Temperature Process (Cont.)

\begin{tabular}{|c|c|c|c|}
\hline $\begin{array}{c}\text { Step } \\
\text { No. }\end{array}$ & & Process & $\begin{array}{c}\text { No. } \\
\text { Wafers } \\
\end{array}$ \\
\hline 33 & $3112 \mathrm{DA}$ & $\mathrm{N}+$ PREDEP, 30M, NOTE $\mathrm{l}$ & 25 \\
\hline 34 & $5111 \mathrm{AA}$ & ETCH, A+C, C5 нPO $+1 M$ & 25 \\
\hline 35 & $1106 \mathrm{AA}$ & CLEAN & 25 \\
\hline 36 & $3107 \mathrm{AF}$ & $\mathrm{N}+\mathrm{DRV}, 30 \mathrm{M}, 1000 \mathrm{C}$ & 25 \\
\hline 37 & $2105 \mathrm{CA}$ & DEP OX, 12KA, FRONTS & 25 \\
\hline 38 & $5100 \mathrm{BB}$ & $747 / 50$, LVA, 3.5S A & 25 \\
\hline 39 & $5124 \mathrm{AA}$ & $T X-100$ PRE-WET & 25 \\
\hline 40 & $5111 \mathrm{AA}$ & $\mathrm{ETCH}, \mathrm{A}+\mathrm{C}, \mathrm{C} 4 \mathrm{HPO}+2 \mathrm{M}$ & 25 \\
\hline 41 & $9200 \mathrm{AA}$ & INSPECTION & 25 \\
\hline 42 & $1100 \mathrm{AA}$ & CLEAN W/SCRUB & 25 \\
\hline 43 & $3107 \mathrm{AB}$ & DRY OX, $60 M$ & 25 \\
\hline 44 & $4112 \mathrm{BB}$ & IMP $A+C$ & 25 \\
\hline 45 & $5124 \mathrm{AA}$ & TX100 DIP & 25 \\
\hline 46 & $5111 \mathrm{BE}$ & $\mathrm{ErCH}, 3 \mathrm{M}$ & 25 \\
\hline 47 & $1106 \mathrm{AA}$ & CLEAN & 25 \\
\hline 48 & $3107 \mathrm{AV}$ & GT $0 x, 700+-25 A, T 15$ & 25 \\
\hline 49 & $3110 \mathrm{HB}$ & $875 \mathrm{C}, 40 \mathrm{M} \mathrm{N} 2 \mathrm{ANN}$ & 25 \\
\hline 50 & $5100 \mathrm{AA}$ & $747 / 60$, LVS, $3.55 \mathrm{~A}$ & 25 \\
\hline 51 & $5124 \mathrm{AA}$ & TX-100 PRE-WET & 25 \\
\hline 52 & $5111 \mathrm{AA}$ & $\mathrm{ETCH} \mathrm{A}+\mathrm{Cl}-3,8-15 \mathrm{HPO}+2 \mathrm{M}$ & 25 \\
\hline 53 & $9200 \mathrm{AA}$ & INSPECTION & 25 \\
\hline 54 & $1100 \mathrm{BB}$ & $25 \mathrm{~A}$ ETCH, $\mathrm{A}+\mathrm{C} 4-6$ & 25 \\
\hline 55 & $9101 \mathrm{AA}$ & MEAS RS\&XJ, $\mathrm{Cl}-3,8-15$ & 25 \\
\hline 56 & $9105 \mathrm{AA}$ & GAET OC $\mathrm{TH}, \mathrm{C} 4-7$ & 25 \\
\hline 57 & $6104 \mathrm{BB}$ & IOKA, A, C5, 6 DOTS, N2 & 25 \\
\hline 58 & $5105 \mathrm{CC}$ & HRI00, LEV6, I2S, A & 24 \\
\hline 59 & $9200 \mathrm{BA}$ & INSPECTION & 24 \\
\hline 60 & $5124 \mathrm{AA}$ & $T X-100$ PRE-WET & 24 \\
\hline 61 & $5113 \mathrm{AA}$ & AL ETCH, A & 24 \\
\hline 62 & $9200 \mathrm{BA}$ & INSPECTION & 24 \\
\hline 63 & $1109 \mathrm{AB}$ & RESIST REM，JI00， A & 24 \\
\hline 64 & 3109AA & SINTER, 20M, A + C5, 5 & 25 \\
\hline
\end{tabular}




\section{lligh Temperature Process (Cont.)}

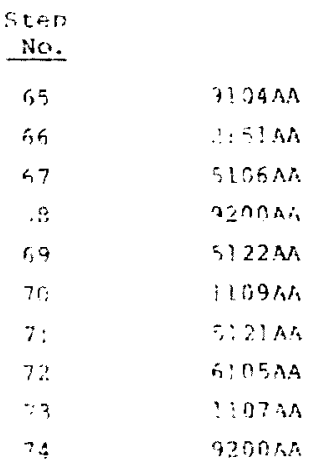

\section{Processs}

OXIDE MEAS, CQ

Ir.

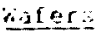

SILUX P-GL, PRONTS, N3

$\therefore 4$

$747 / 110$, IV?, A

14

INSPECTION

24

H)POA/HE FICH, A

24

J-?OON STRI:, A

24

BACK P:TCH W STICK, O

24

$\therefore 4$

CR AU, AACKS, $C$

$\therefore 4$

SCRUB

$\because 4$

INSFECTION, DLAO

r. 


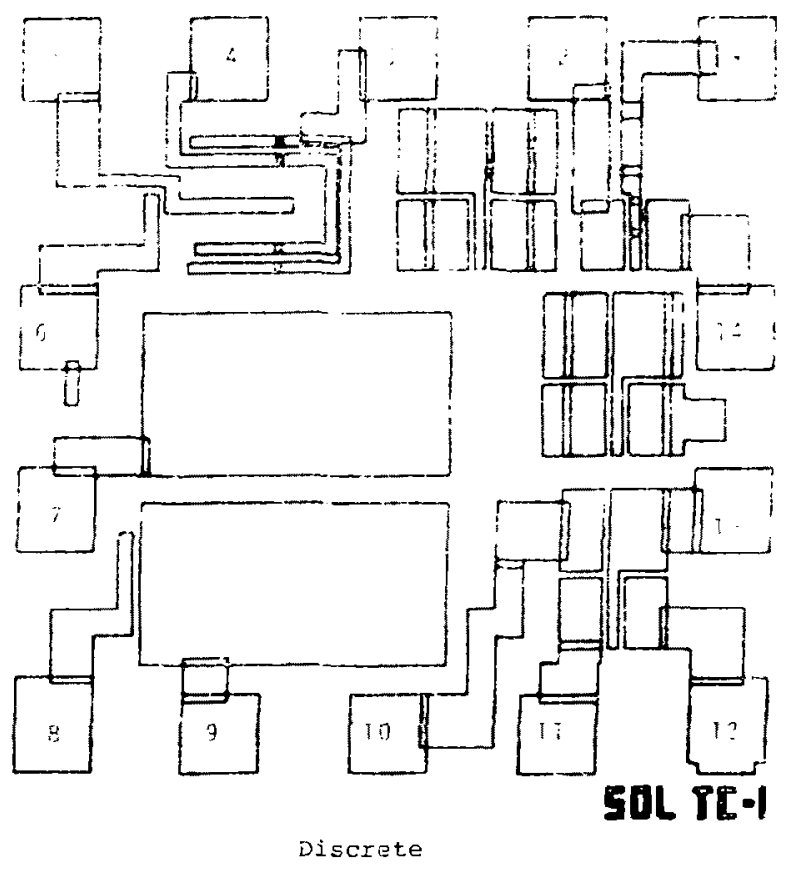


$V_{G} @ 10 \mu a \quad T C-1$ N-CHANNEL WAFER 1

- $25^{\circ} \mathrm{C}$

ㅁ $150^{\circ} \mathrm{C}$

$\triangle 250^{\circ} \mathrm{C}$

$\times 300^{\circ} \mathrm{C}$

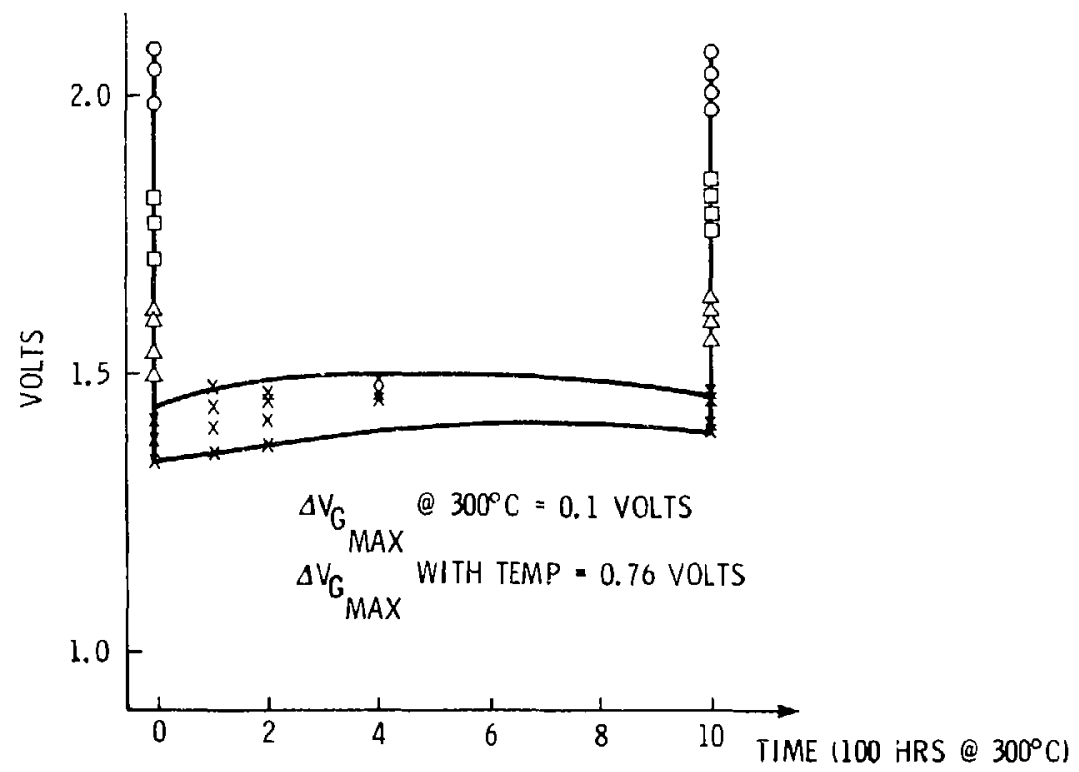


$V_{G} @ 10 \mu \mathrm{a} \quad$ TC-1 P-CHANNEL WAFER I

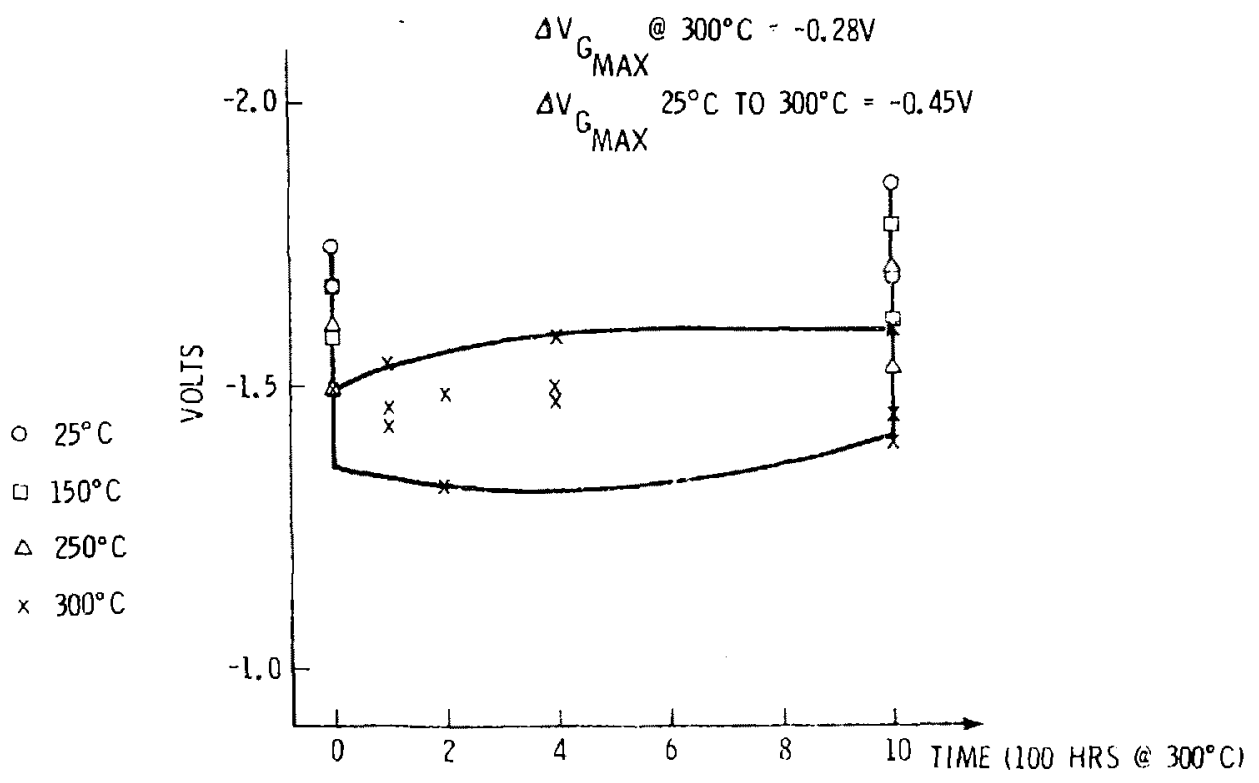




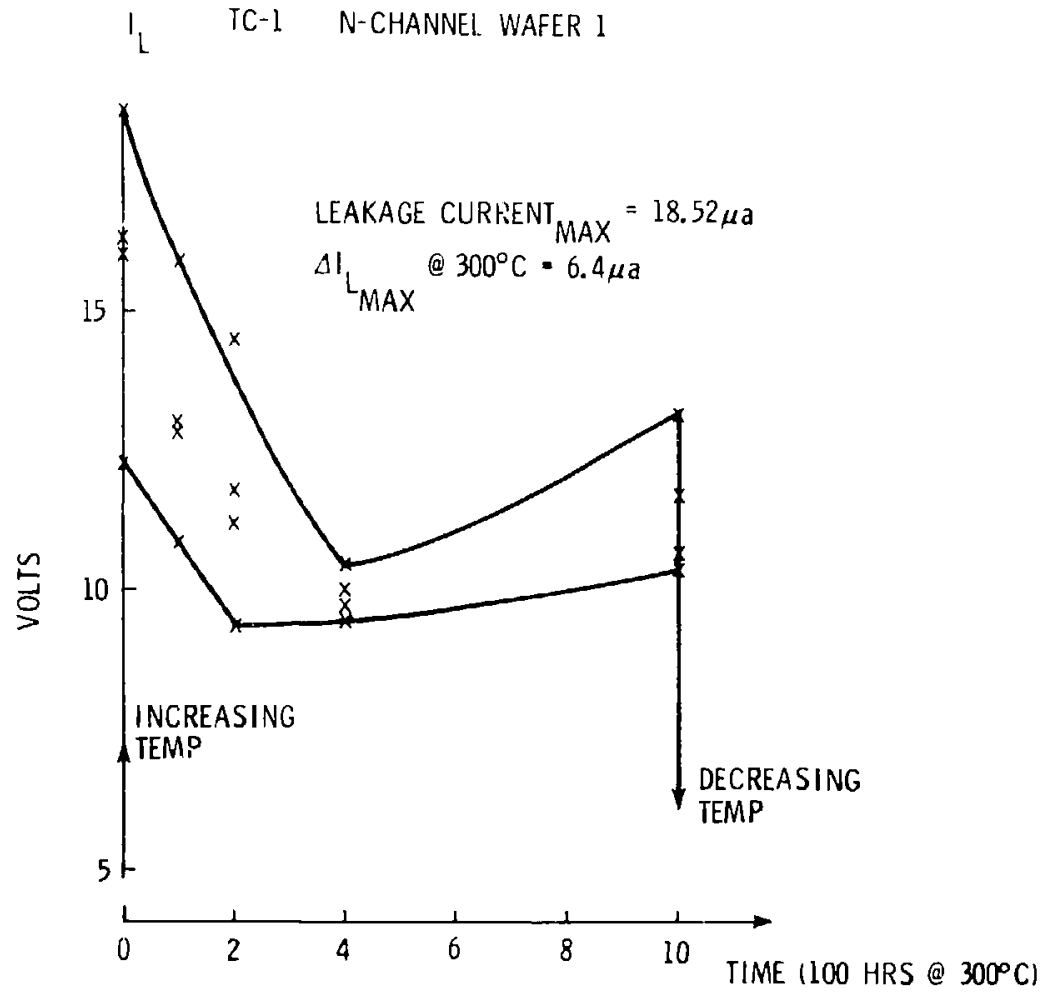




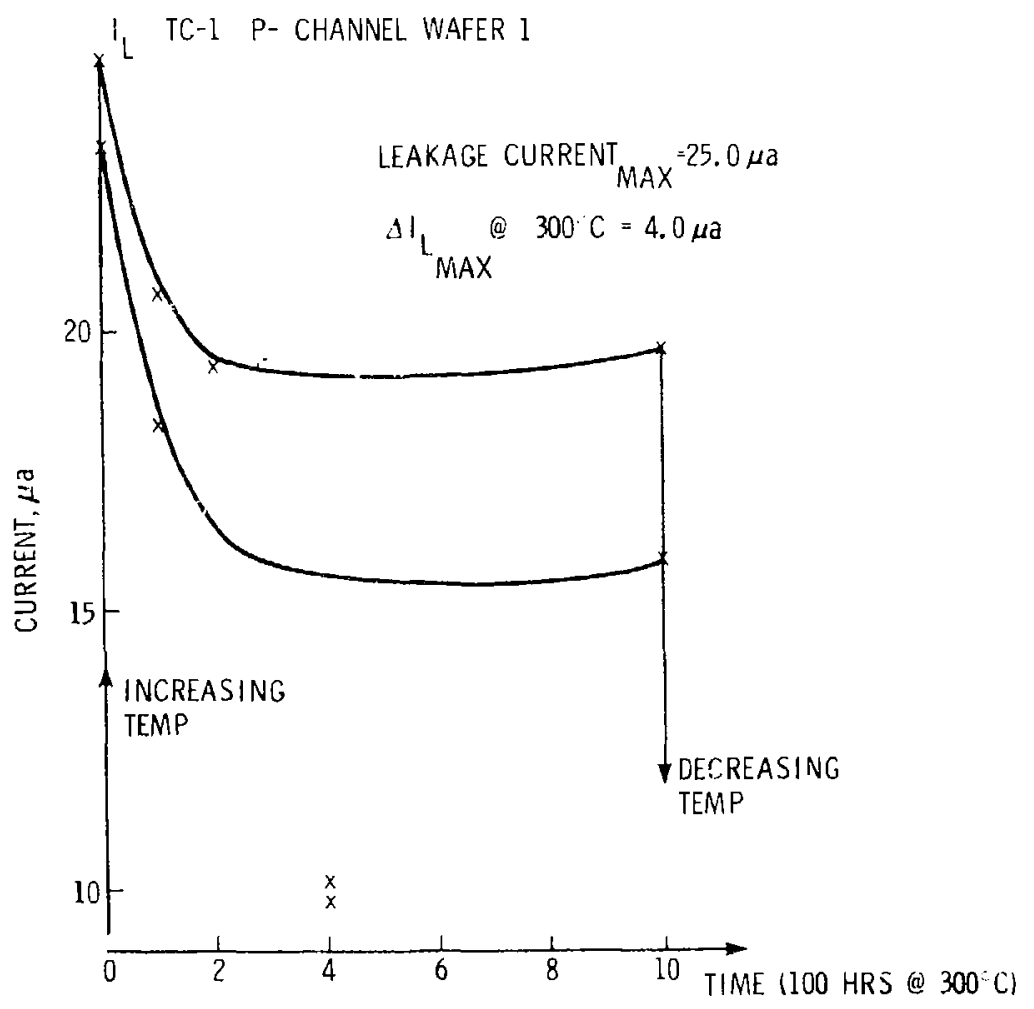


$V_{G} @ 10 \mu a$ TC-1 N-CHANNEL WAFER 7

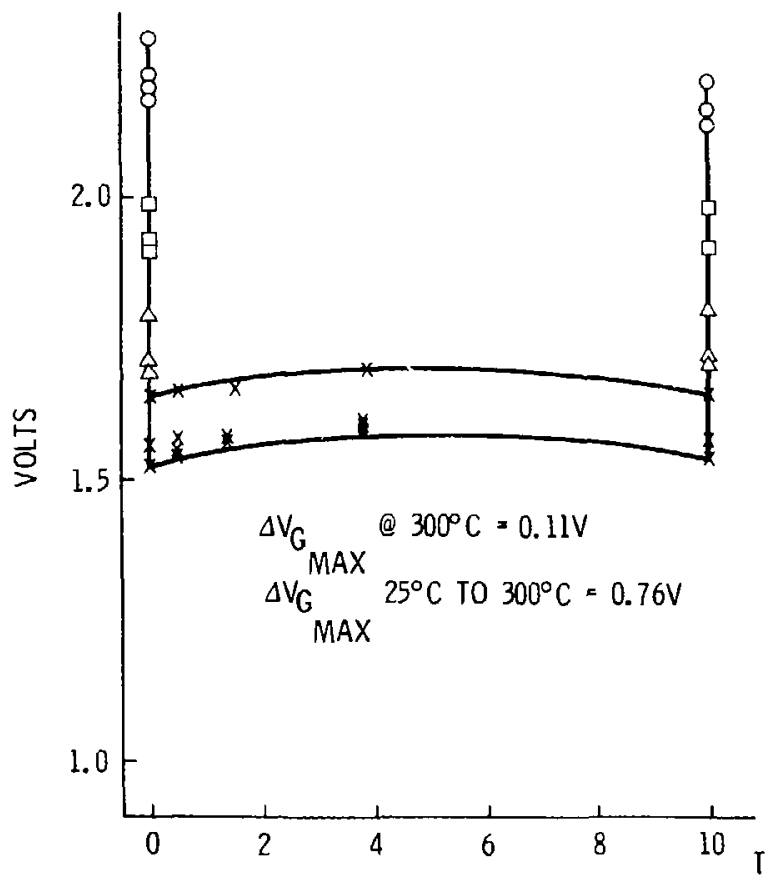

- $25^{\circ} \mathrm{C}$

- $150^{\circ} \mathrm{C}$

$\triangle 230^{\circ} \mathrm{C}$

$\times 300^{\circ} \mathrm{C}$ 


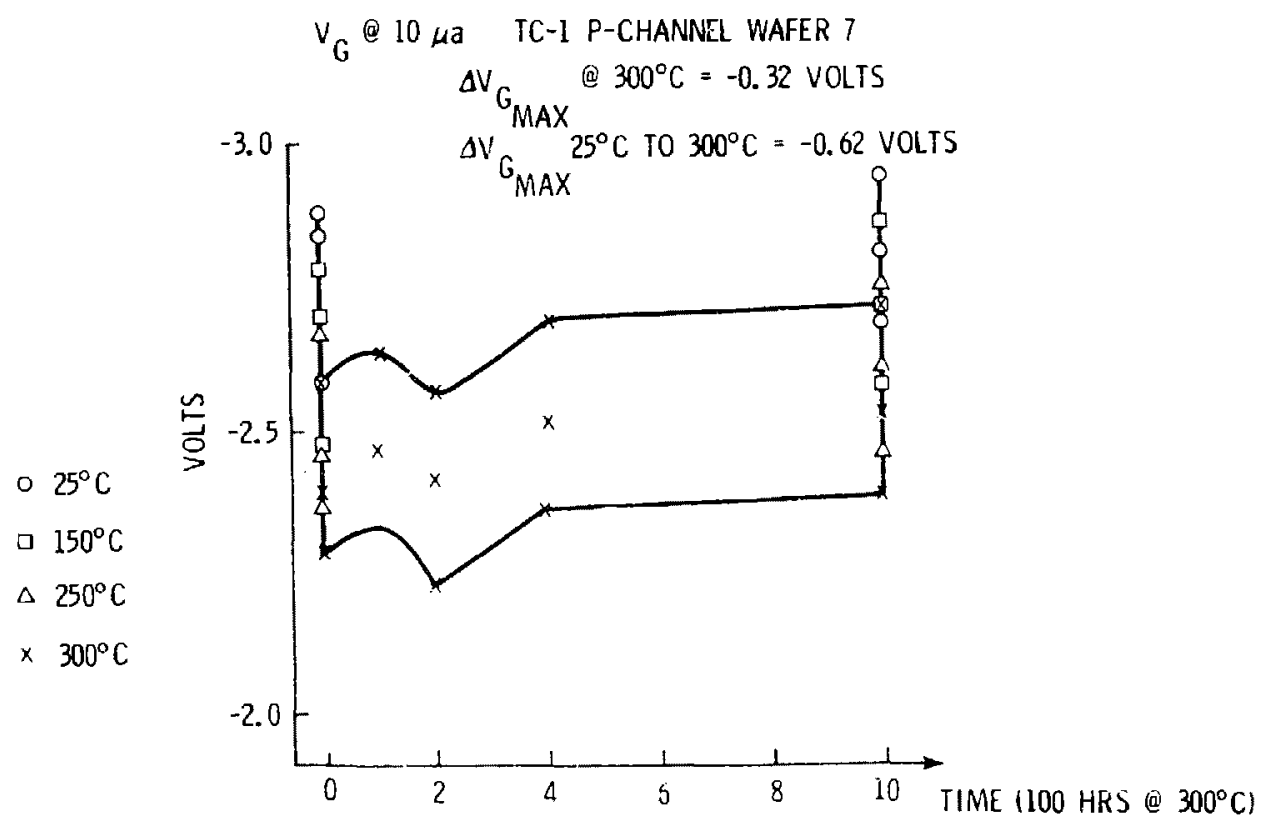




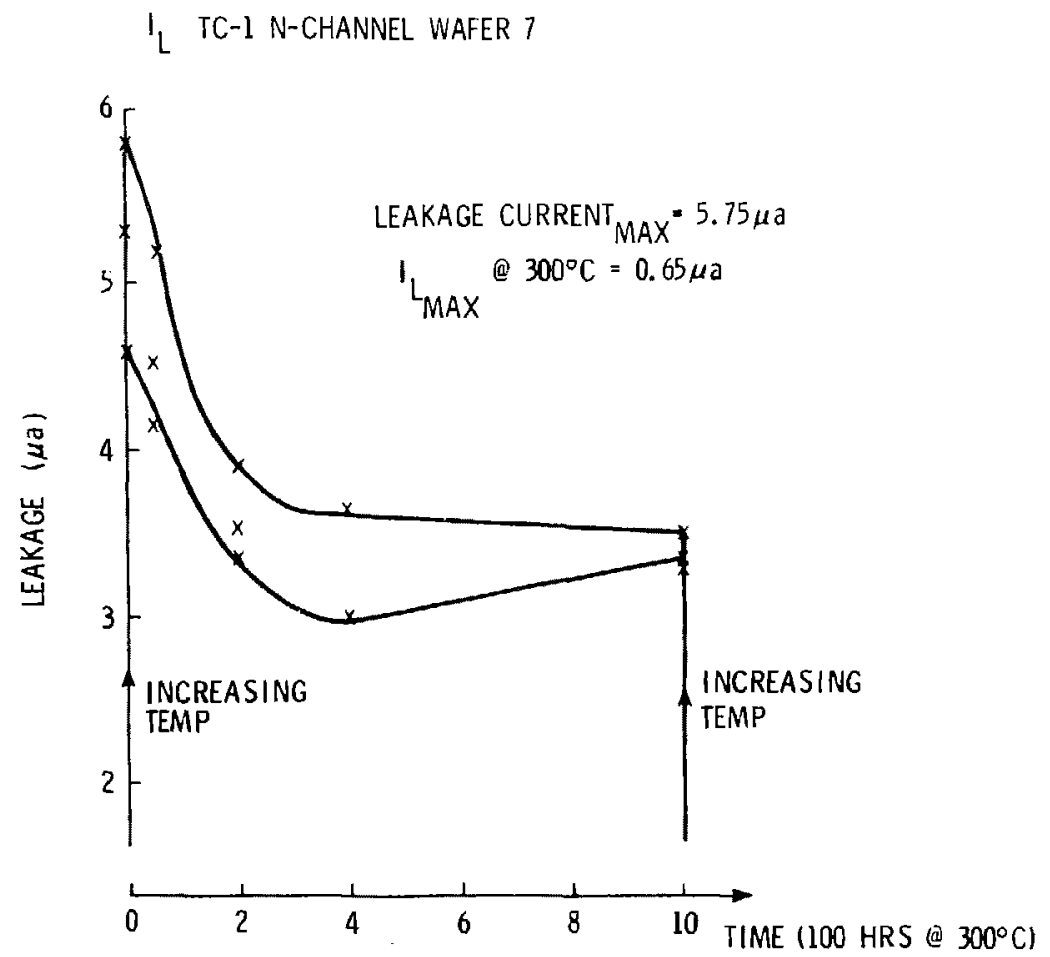




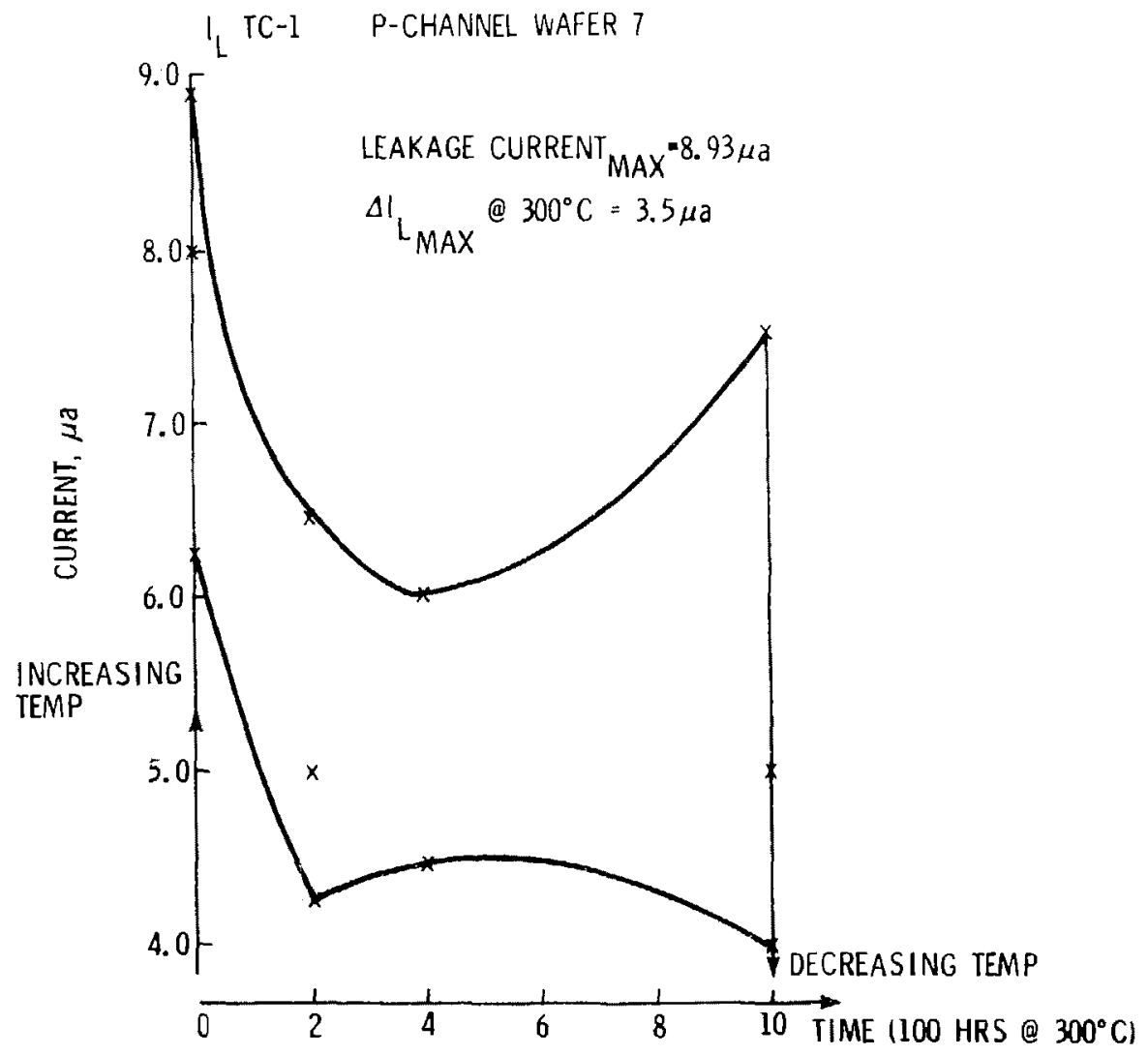


$V_{G} @ 10 \mu \mathrm{a}$ TC-1 N-CHANNEL WAFER 9

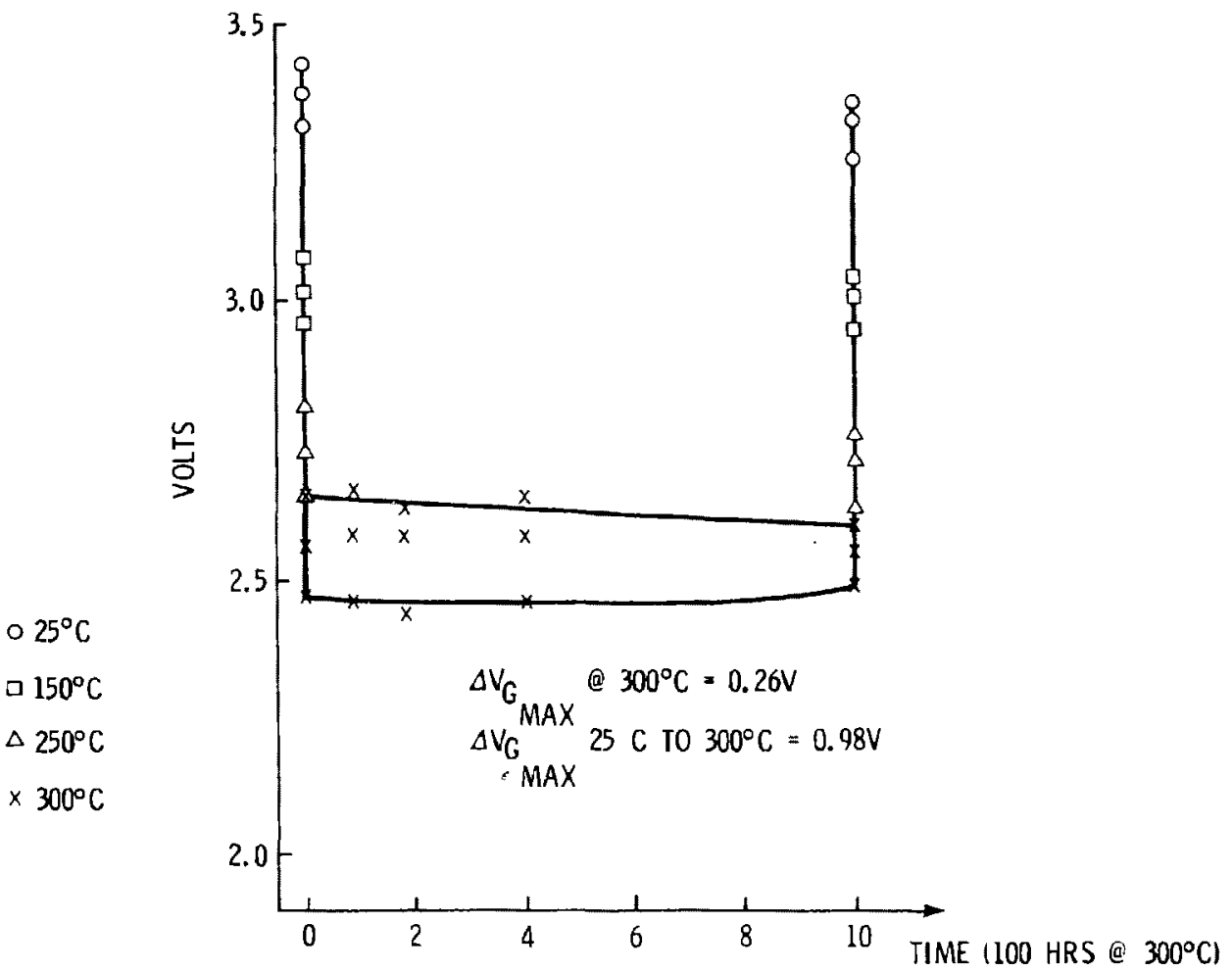




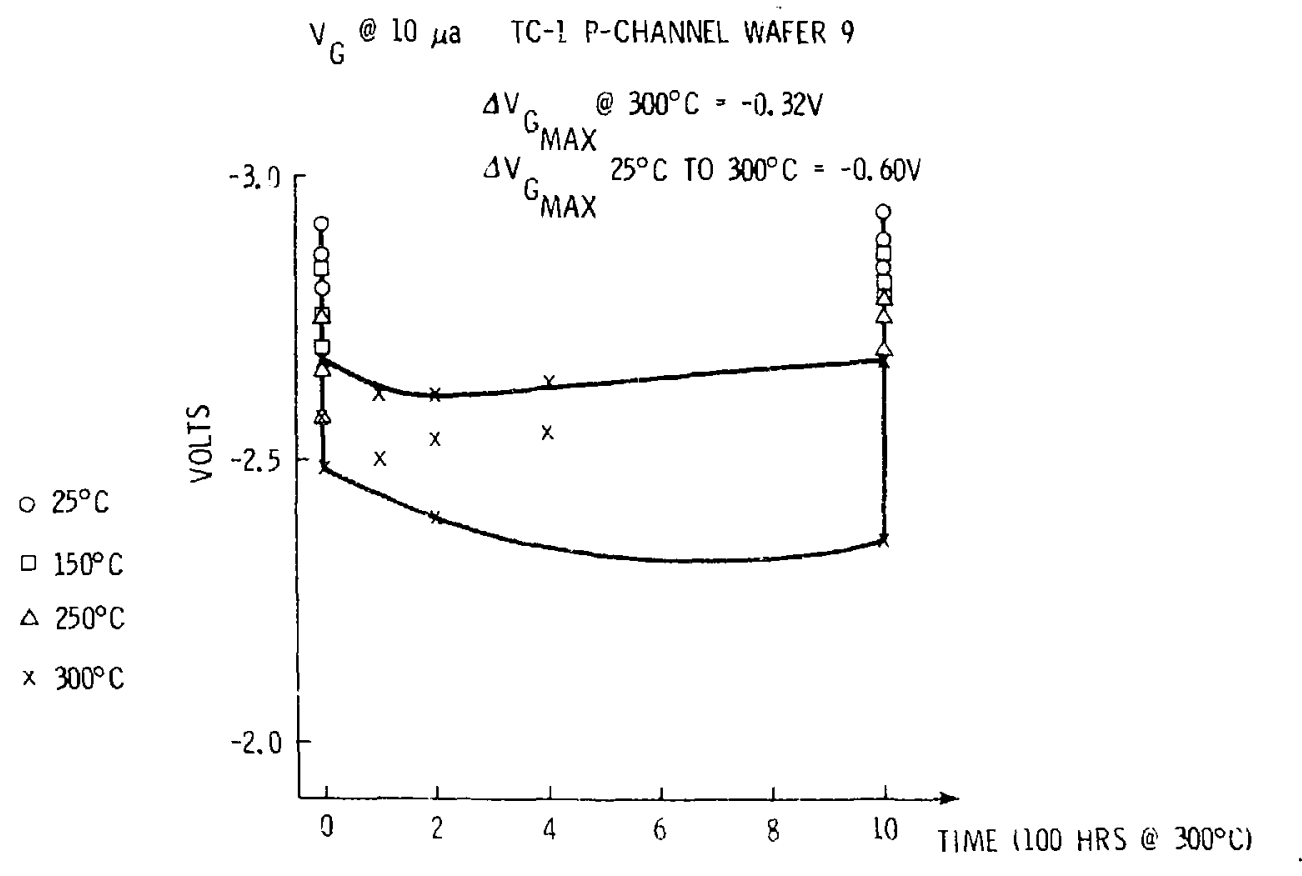


I TC-1 N-CHANNEL WAFER 9

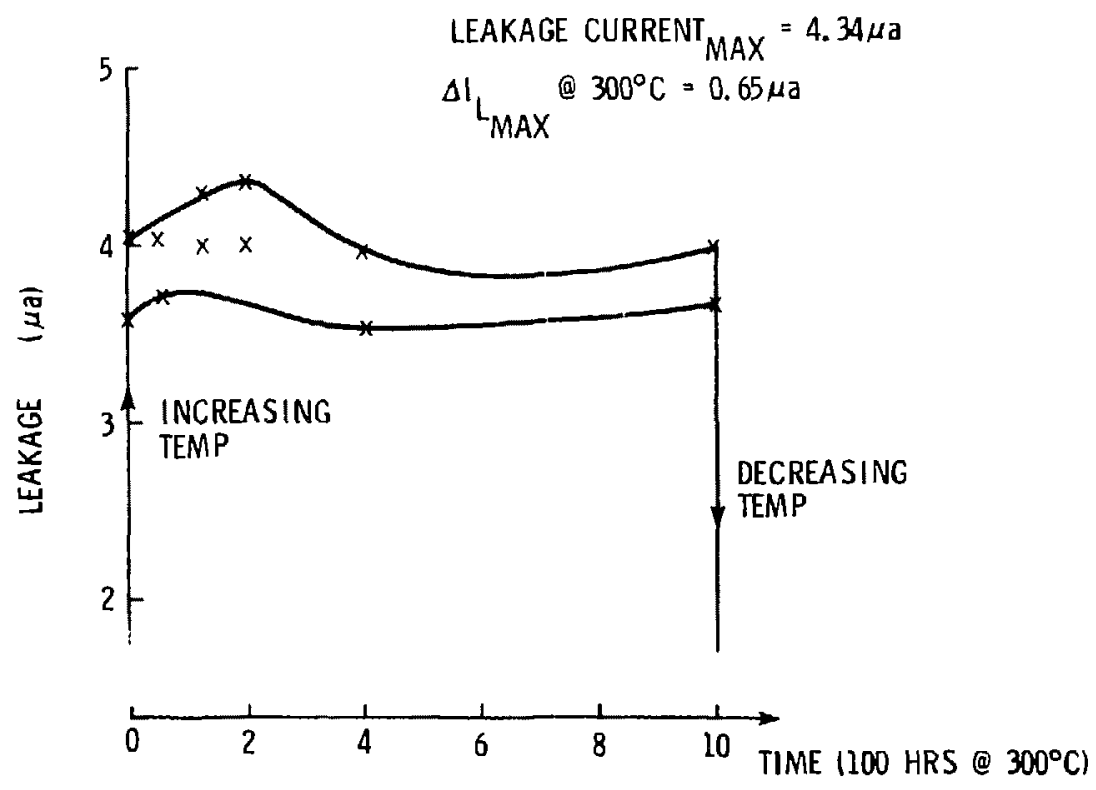




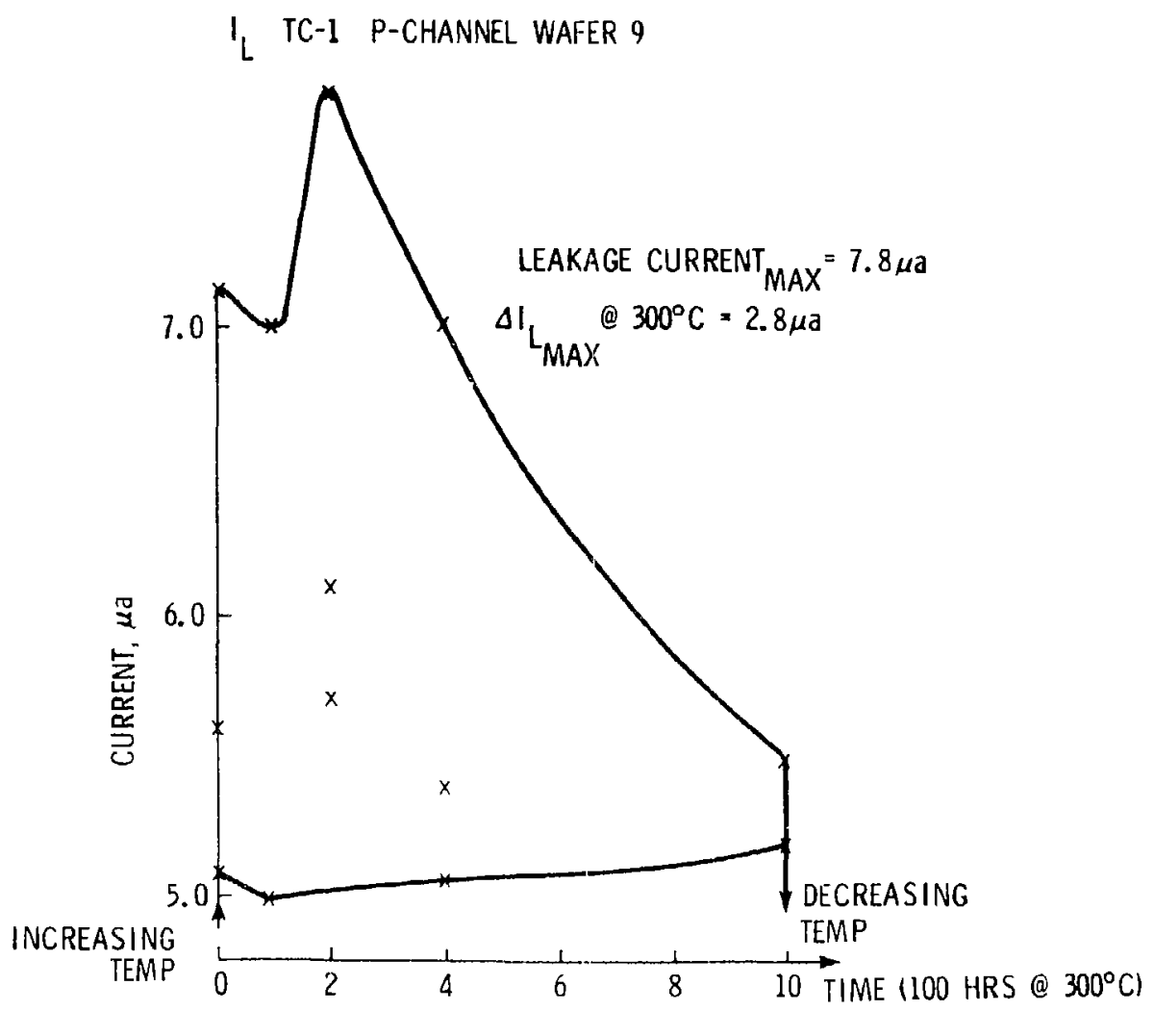




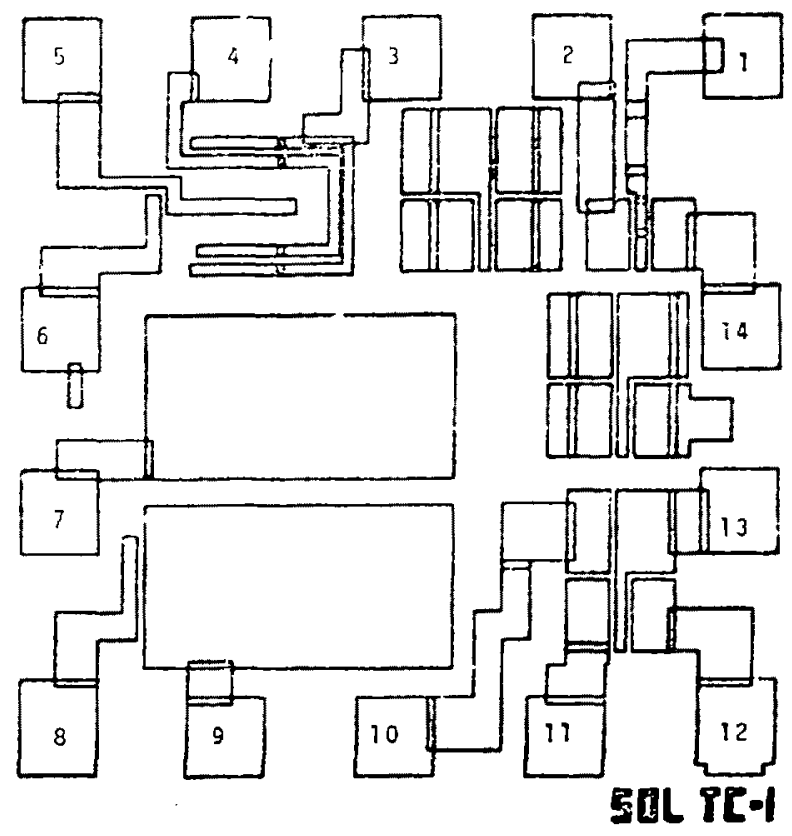

Inverter 


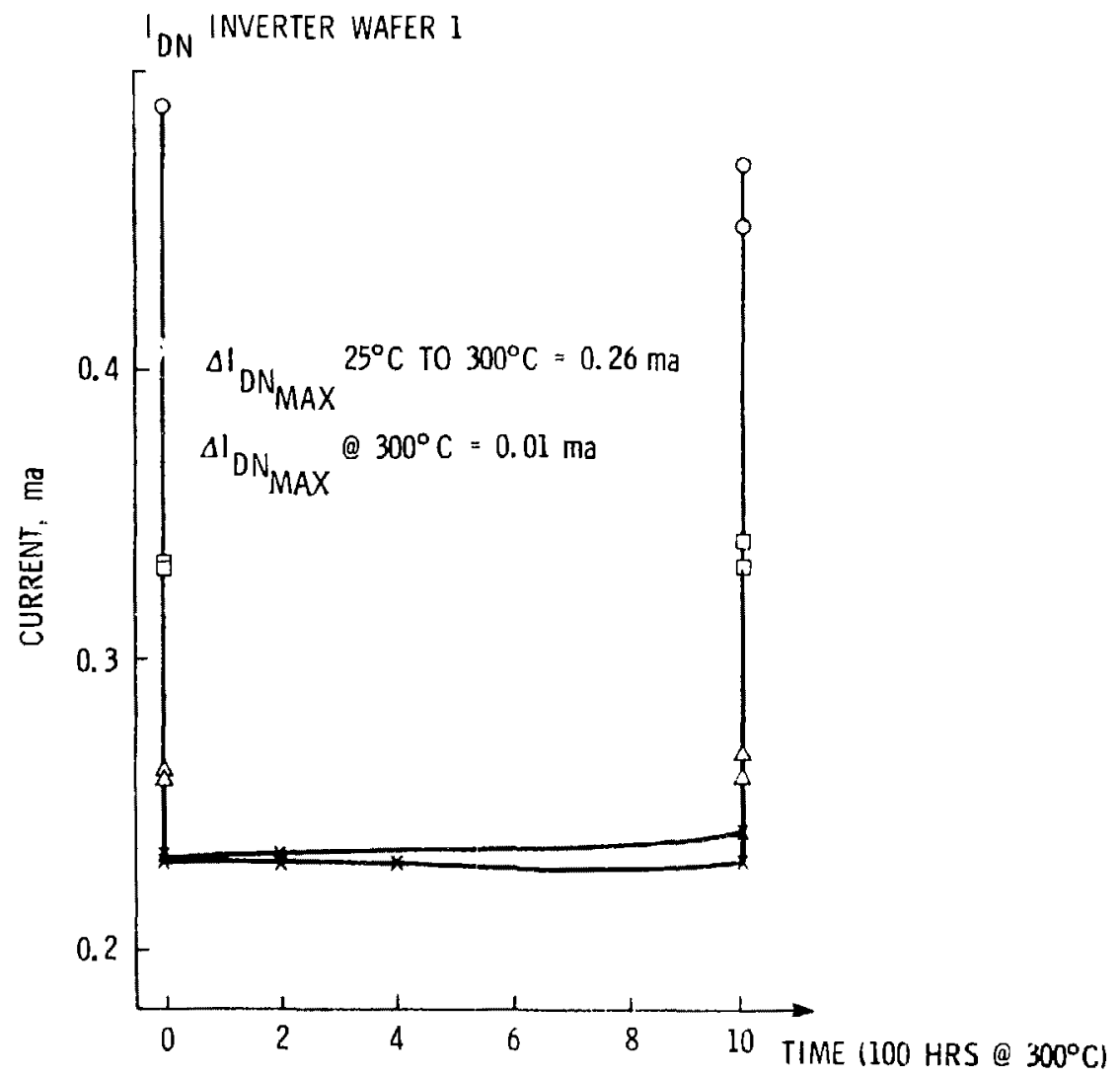




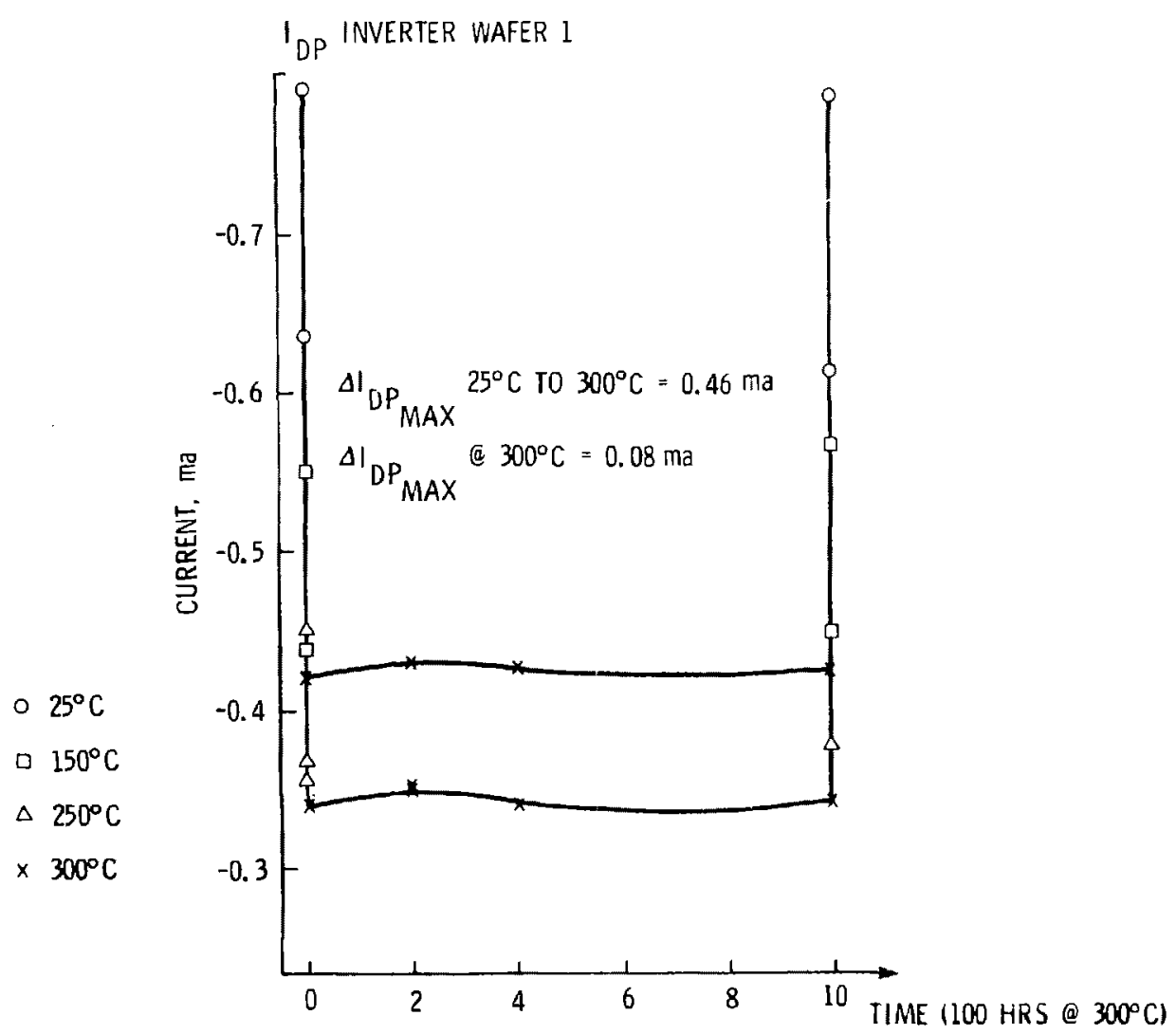




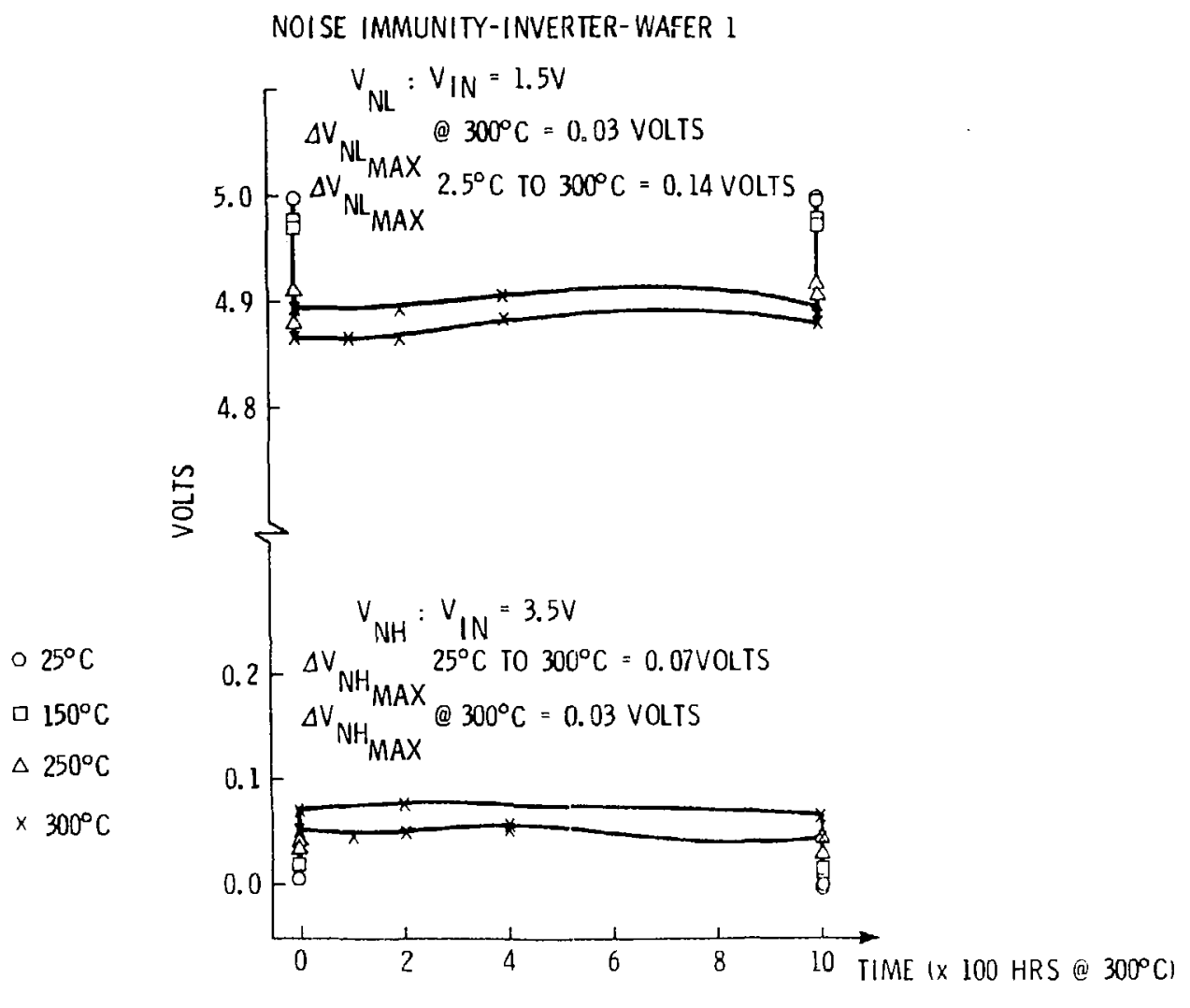




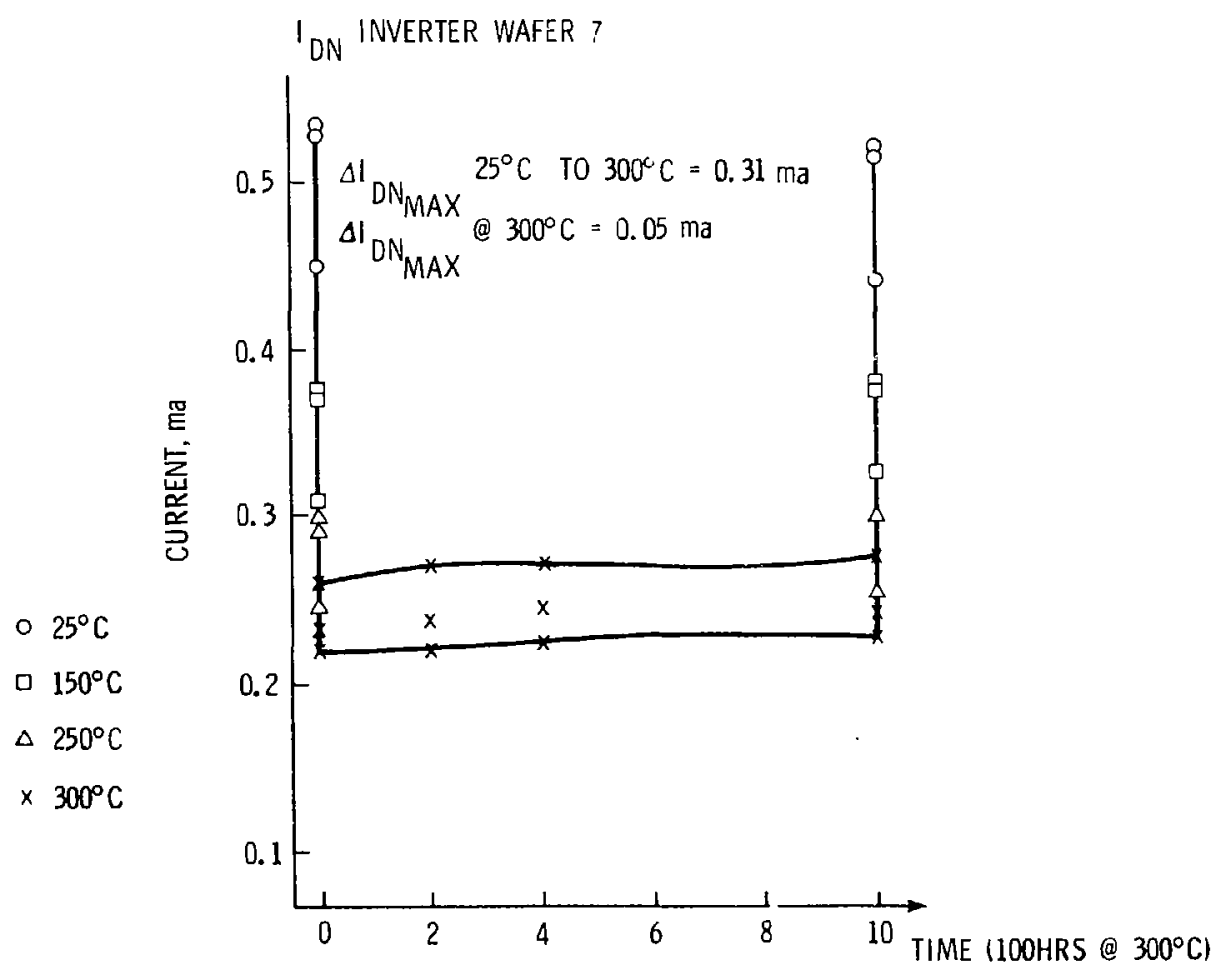




$$
I_{D P} \text { INVERTER WAFER } 7
$$

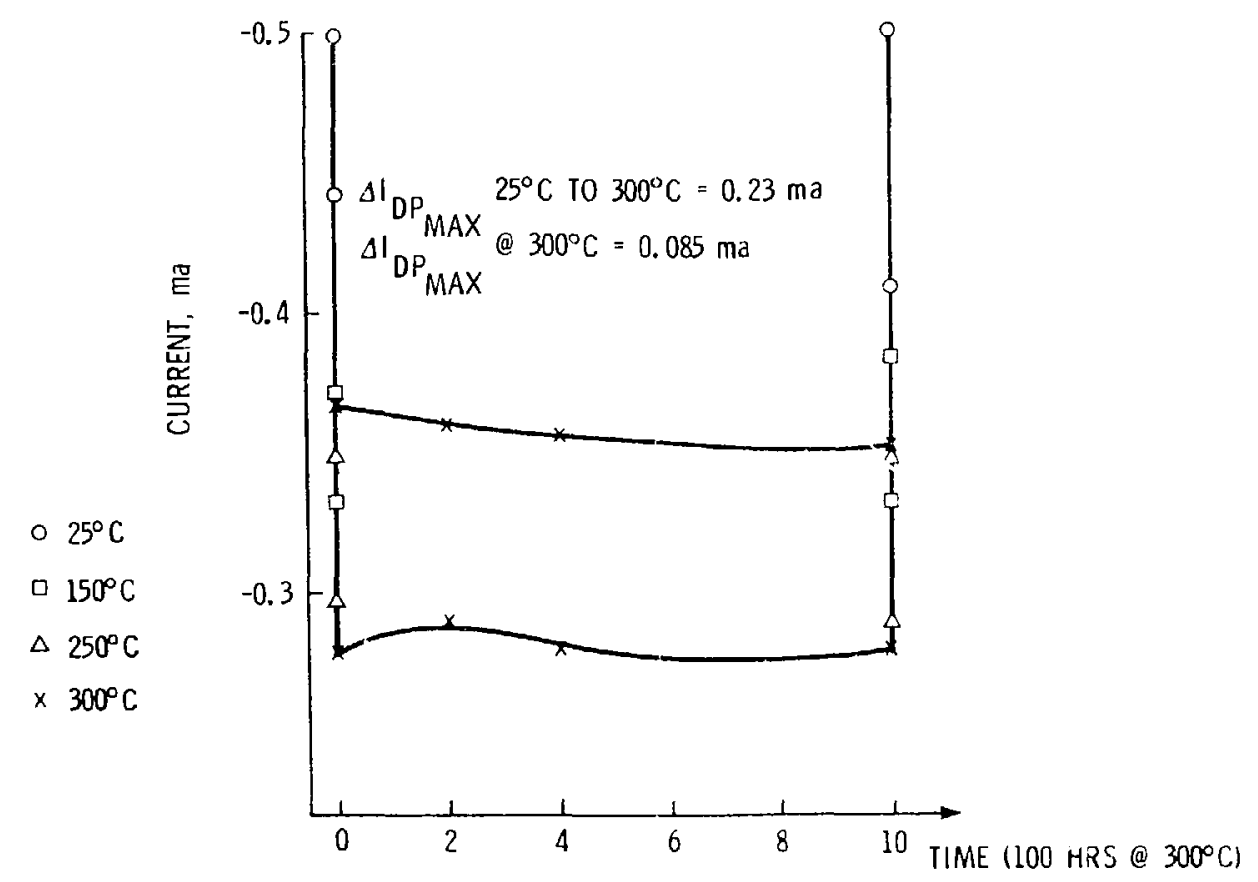


INVERTER-NOISE IMMUNITY-WAFER 7

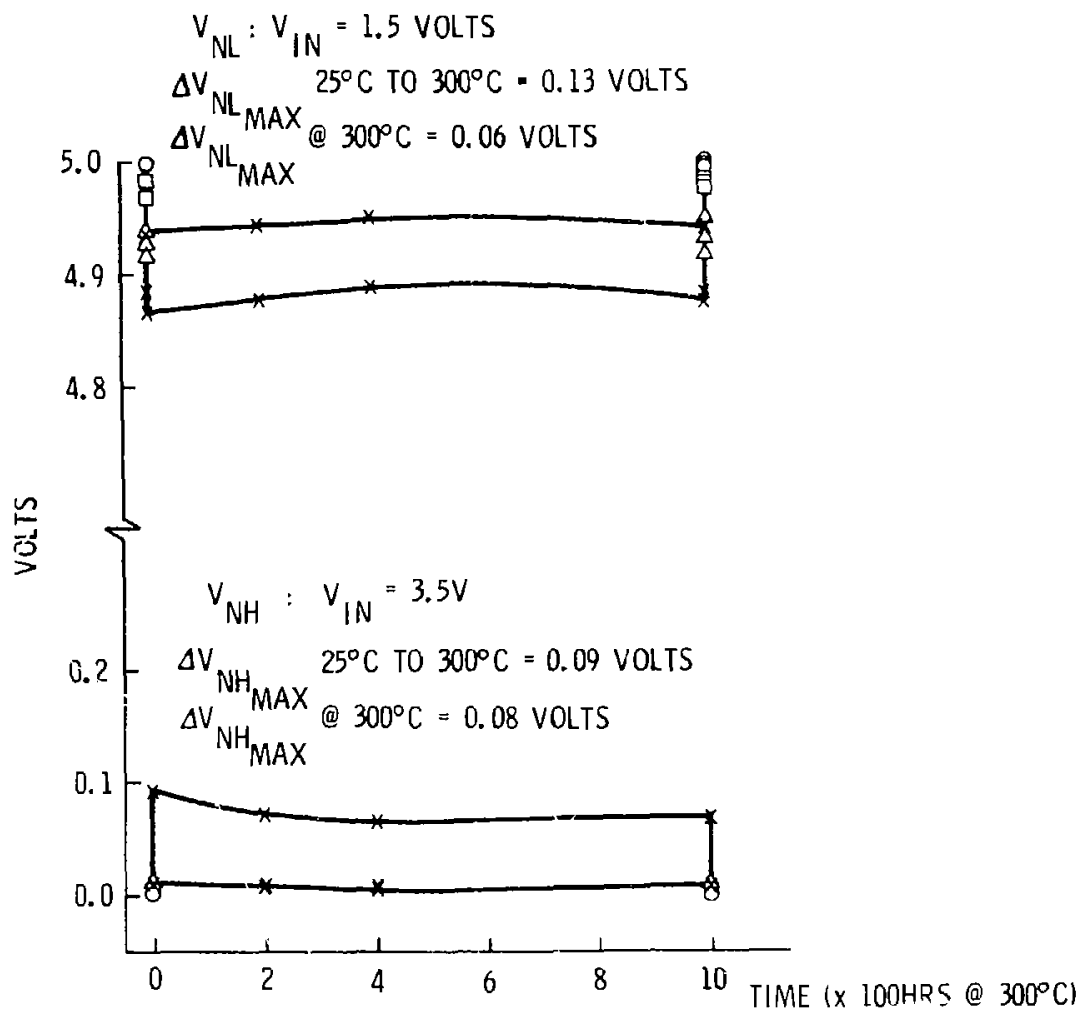


$I_{\text {DN }}$ INVERTER WAFER 9

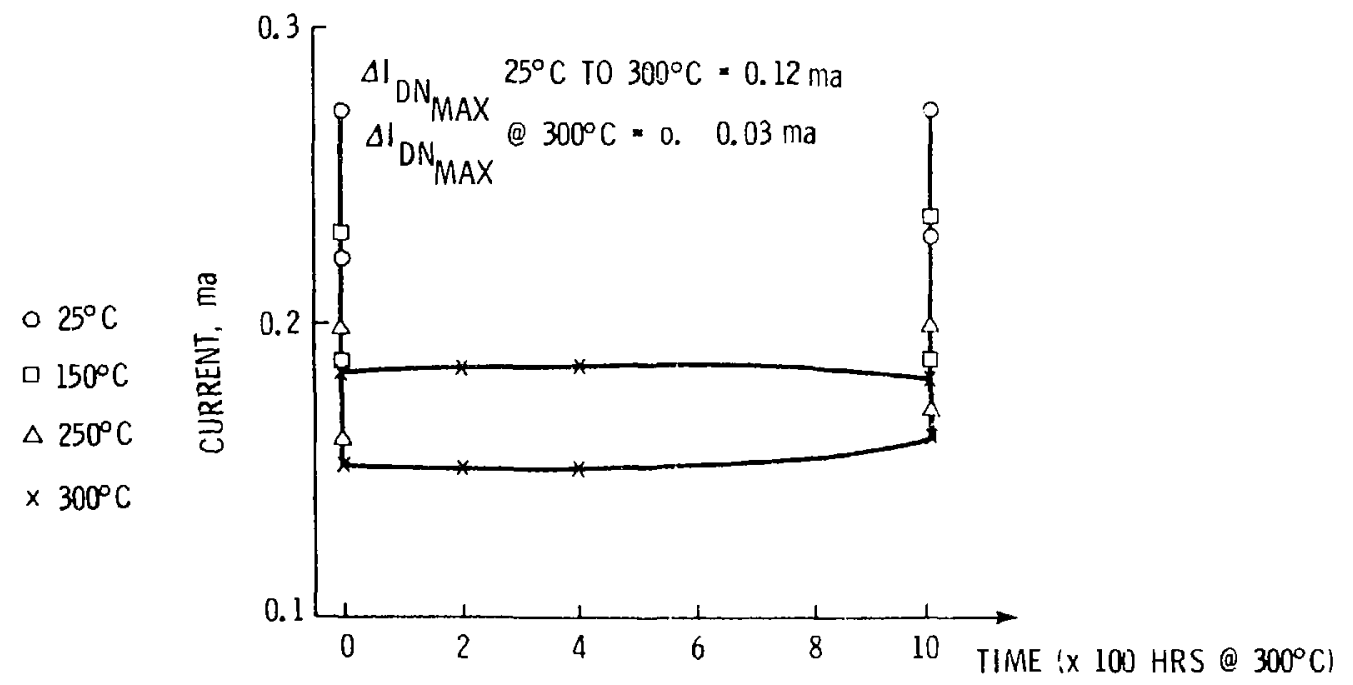


$I_{D P}$ INVERTER WAFER 9

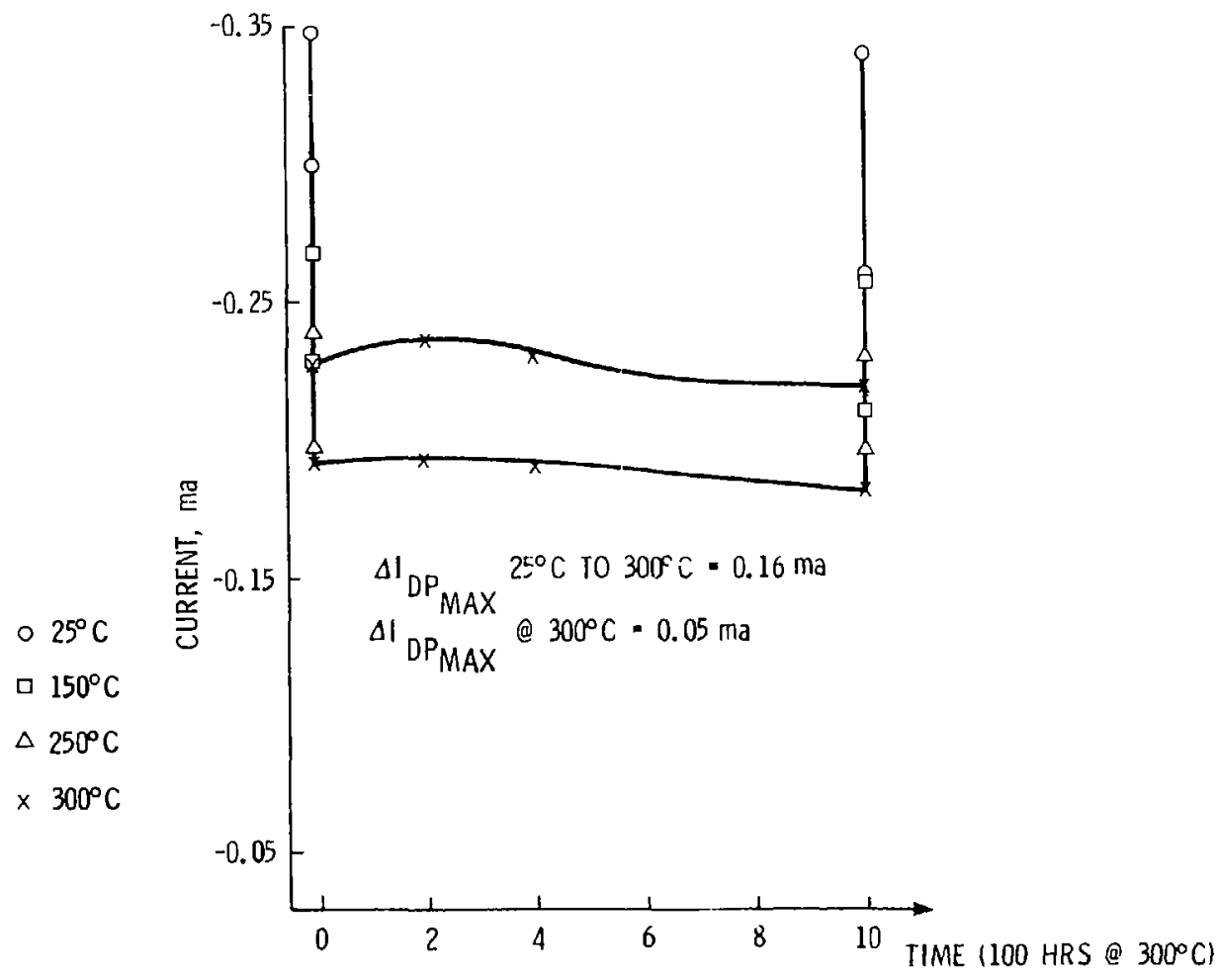



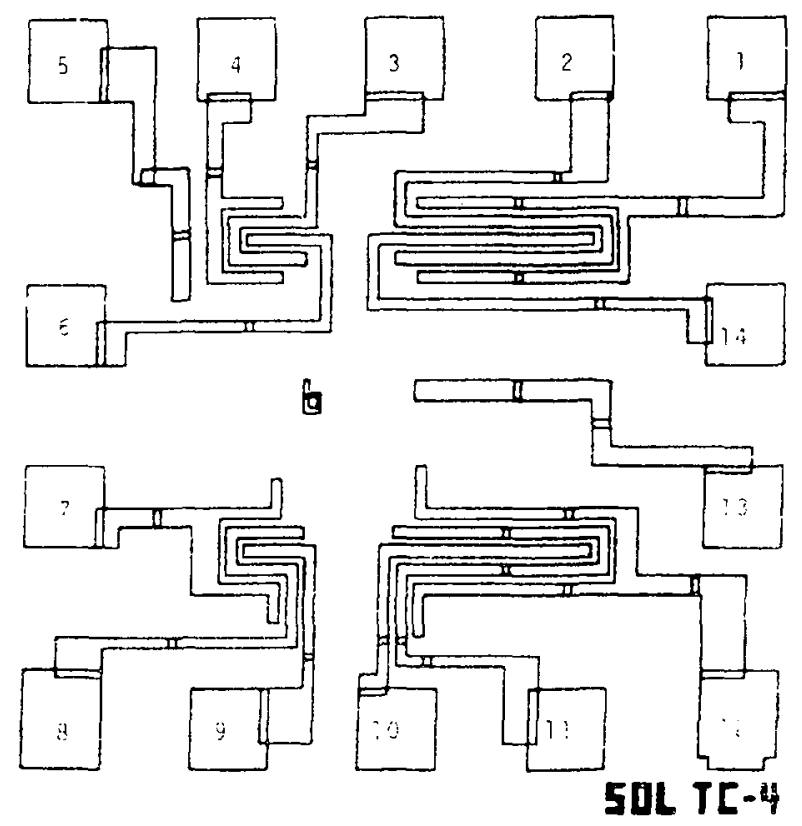

Tesi Chip 


\section{Glossary of Technical Terms}

BAND GAP

CARRTFR

CMOS

DEPLERION (tegion)

DOPE， DOPING

DRAIN

FERMI LEVEL

FIELD EFFEC' TRANSISTOR

FLAT PACK

SATE

$\because \because P S$ RIVG

$\because: \Sigma \equiv$

$\because \because \div \because \because$

$\therefore+\cdots+\cdots=$

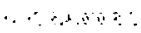

The difference in energy between two bands of energy in a semiconductor or irisulator.

Also known as charge carrier--a mobile plectron or hole (see HOr,E).

Complementary Metal oxide

Semiconductor--a device that combines a p-type MOS device with an n-type MOS device (see PMOS, NMOS).

Region between $n$ - and p-type semiconductor. Region depleted of carriers in semiconductor junction.

Adding impurities to a semiconductor to produce n- or p-type material.

An electrode in a thin-film transistor.

Also called Fermi energy; the energy level that is constant throughout the crystal.

A transistor in which a transverse electric field modulates the conductance between two nodes.

A thin, rectangular, ceramic package, the connecting pins projecting from the edges.

Modulating terminal in a FET.

Doped region that decreases parasitic transistor action.

A vacant electron energy state which behaves as if it were a positively charged particle.

The region of transition between the two semiconducting regions, in this case, the pn juncion.

To coat or impregnate with metal. SEE n-TYPE SEMICONDUCTOR. 
NMOS

n-TYPE CONDUCTIVITY

D-TYPE. SEMICONDUCTOR

PASSIVATION

P-CHANNEL

p:Mos

P-TYPE CONDUCTIUITY

P-TYPE SEMICONDUCTOR

P-WELL

SUBSTRATE

TRANSCONDUCTANCE

TRAPPING SIGHT

ZERO TEMPERATURE COEFFICIENT POINT n-type MOS device isee cMOS, n-TYPE SEMICONDUCTORI.

conduction associated with electrons $i$ in a remiconductor (se a e-TYPF) CONDUCTIVITY) .

A semiconductor in which clectuon density exceeds that of the hoies.

Growing a layer of oxide on the surliace of a semiconductor thereby isolating it from the environment and providing electrical stability.

SEE P-TYPE SEMICONDUCTOR.

p-rype yos device isee cMOS, p-TYPF. SEMI CONDIJTOR) .

Conductivity associated with heles in a semiconductor (see n-TYPE SEMI CONDUCTOR .

A semiconductor in which excess mobile hole concentration is very bi. Gh.

P region in which n-channel

transistors are made.

The material on which a microcircuit is huilt.

The change in drain current divided by the change in gate voltage causing it, if all other voltages are constant.

Allowable energy state within band gap.

That point on the transfer curve whicn is independent of temperature. 


\section{Bibliography}

Leitstiko, O., JI., and A. S. Grove, "Breakdown of P'anar Silicon Junctions," Solid-State Electronics, 9, P. 847 (1966).

Pearson, G. L, and J. Bardeen, "Electrical Properties of Pure Silicon and Silicon Alloys Containing Boron and Phosphorus," Phys. Rev., 75, P. 865 (1949).

Sze, S. M.. and G. Gibbons, "Effect of Junction Curvature on Breakdown Voitage in Semiconductors," Solid-State Electronics, 9 (1965). 